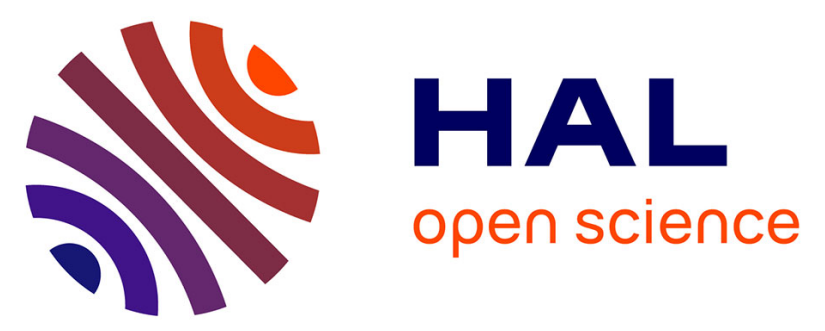

\title{
Effect of Alkyl Side Chain Length on Doping Kinetics, Thermopower, and Charge Transport Properties in Highly Oriented F 4 TCNQ-Doped PBTTT Films
}

Vishnu Vijayakumar, Elena Zaborova, Laure Biniek, Huiyan Zeng, Laure Herrmann, Alain Carvalho, Olivier Boyron, Nicolas Leclerc, Martin Brinkmann

\section{To cite this version:}

Vishnu Vijayakumar, Elena Zaborova, Laure Biniek, Huiyan Zeng, Laure Herrmann, et al.. Effect of Alkyl Side Chain Length on Doping Kinetics, Thermopower, and Charge Transport Properties in Highly Oriented F 4 TCNQ-Doped PBTTT Films. ACS Applied Materials \& Interfaces, 2019, 11 (5), pp.4942-4953. 10.1021/acsami.8b17594 . hal-02194242

\section{HAL Id: hal-02194242 \\ https://hal.science/hal-02194242}

Submitted on 7 Dec 2021

HAL is a multi-disciplinary open access archive for the deposit and dissemination of scientific research documents, whether they are published or not. The documents may come from teaching and research institutions in France or abroad, or from public or private research centers.
L'archive ouverte pluridisciplinaire HAL, est destinée au dépôt et à la diffusion de documents scientifiques de niveau recherche, publiés ou non, émanant des établissements d'enseignement et de recherche français ou étrangers, des laboratoires publics ou privés. 


\section{Impact of Alkyl Side Chain Length on Doping Kinetics, Thermopower and Charge Transport Properties in Highly Oriented $\mathrm{F}_{4}$ TCNQ-Doped PBTTT films}

Vishnu Vijayakumar ${ }^{1}$, Elena Zaborova ${ }^{2,3}$, Laure Biniek $^{1}$, Huiyan Zeng $^{1}$, Laurent Herrmann $^{1}$, Alain Carvalho ${ }^{1}$, Olivier Boyron ${ }^{4}$, Nicolas Leclerc $^{3}$ and Martin Brinkmann ${ }^{1^{*}}$

(1) Université de Strasbourg, CNRS, ICS UPR 22, F-67000 Strasbourg, France

(2) CiNaM, UMR 7325, Université Aix Marseille, Campus de Luminy, Case 913, 13288 Marseille Cedex 9, France

(3) Université de Strasbourg, CNRS, ICPEES UMR 7515, F-67087 Strasbourg, France

(4) Université de Lyon 1, CPE Lyon, CNRS UMR 5265, Laboratoire de Chimie Catalyse Polymères et Procédés (C2P2), Bat 308F, 43 bd du 11 Novembre 1918, 69616 Villeurbanne, France. 
Figure for Title of content
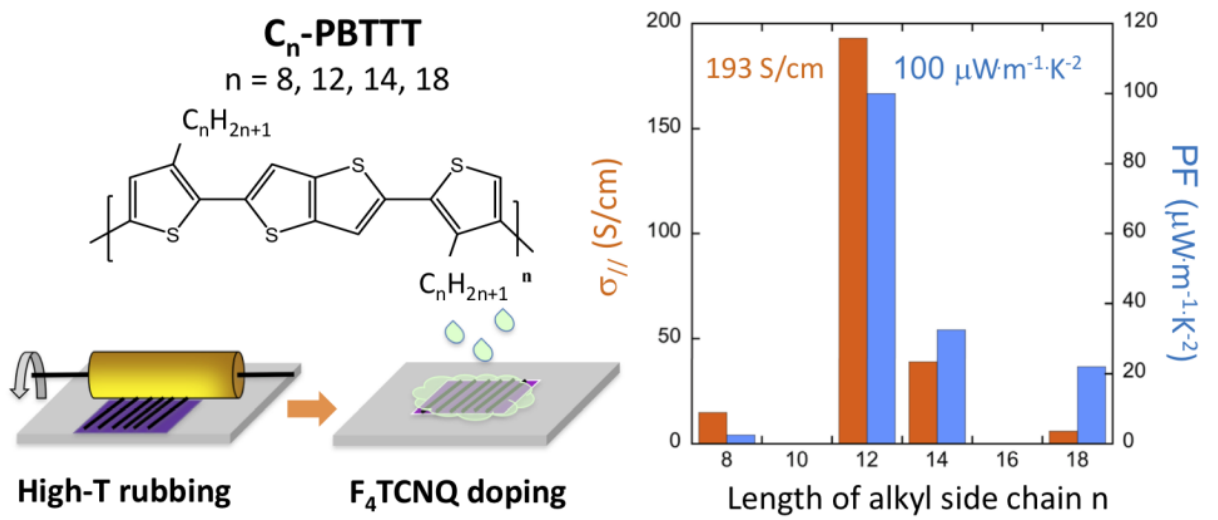

Keywords: Organic Thermoelectric, Conducting Polymers, Structure, Thin films, Doping. 


\begin{abstract}
Doping of polymer semiconductors such as PBTTT with acceptor molecules such as $\mathrm{F}_{4}$ TCNQ is widely used to tune the charge transport and thermoelectric (TE) properties in thin films. However, the mechanism of dopant insertion in the polymer matrix, the insertion kinetics and the ultimate doping levels reached have been investigated only marginally. This contribution addresses the impact of alkyl side chain length on the doping mechanism of a series of PBTTTs with linear side chains ranging from $n$-octyl to $n$-octyldecyl. The study focuses on thin films oriented by high temperature rubbing and sequentially doped in $\mathrm{F}_{4} \mathrm{TCNQ}$ solution. Structure-property correlations are established as a function of side chain length by a combination of Transmission Electron Microscopy, polarized UV-Vis-NIR spectroscopy and charge transport / thermopower measurements. Intercalation of $\mathrm{F}_{4} \mathrm{TCNQ}$ into the layers of side chains results in the expansion of the lattice along the side chains and the contraction along the $\pi$-stacking direction for all polymers. The extent of lattice expansion decreases with increasing side chain length. UV-vis spectroscopy demonstrates integer charge transfer for all investigated PBTTTs. The doping kinetics and final doping level depend on both the side chain length and packing. Highly disordered $n$-octyl and crystalline n-octyldecyl side chain layers tend to hamper dopant diffusion in the side chain layers contrary to $n$-dodecyl side chains that can host the highest proportion of dopants. Consequently, the best TE properties are observed for $\mathrm{C}_{12}$-PBTTT films. Alignment of the polymers enhances significantly the TE performance by increasing the charge conductivity and the thermopower along the rubbing direction. Aligned films of $\mathrm{C}_{12}$-PBTTT show charge conductivities of $193 \mathrm{~S} / \mathrm{cm}$ along the rubbing direction and power factors of approx. 100 $\mu \mathrm{W} \cdot \mathrm{m}^{-2} \cdot \mathrm{K}^{-1}$ versus a few $\mu \mathrm{W} \cdot \mathrm{m}^{-2} \cdot \mathrm{K}^{-1}$ for non-oriented films.
\end{abstract}




\section{Introduction.}

Doping of semi-conducting polymers is a simple yet powerful way to control their charge transport properties by tuning the charge carrier densities. Depending on the doping level, different applications can be envisioned in plastic electronics. Low dopant concentrations can be used in blends of semi-conducting and insulating polymers to enhance on/off ratio and charge mobilities in Organic Field Effect Transistors (OFET).(1,2) Doped interface layers can ease charge injection at metallic electrodes.(3) More recently, Crispin and coworkers demonstrated remarkable thermoelectric properties of conducting polymers such as poly(3,4-ethylenedioxythiophene) - tosylate (PEDOT-Tos) by fine tuning the doping level in the thin films. (4) Another challenging system, of high interest to the scientific community, is regioregular poly(3-hexylthiophene) (P3HT) doped with 2,3,5,6-tetrafluoro-7,7,8,8tetracyanoquinodimethane $\left(\mathrm{F}_{4} \mathrm{TCNQ}\right)$. The method of doping was found to impact strongly the resulting charge conductivity in thin films. Blending P3HT with $\mathrm{F}_{4} \mathrm{TCNQ}$ in solution results in poor charge conductivities. (5-9) Conversely, sequential doping of crystalline P3HT films by spin-coating or by dipping into a solution of $\mathrm{F}_{4} \mathrm{TCNQ}$ in an orthogonal solvent results in improved conductivities approaching $10 \mathrm{~S} / \mathrm{cm}$. (4-10) As a consequence, the charge conductivity in sequentially doped $\mathrm{P} 3 \mathrm{HT}$ can be up to ten times higher than that of doped materials prepared from blends in solution. Different mechanisms of doping have been considered: formation of a charge transfer complex with partial charge transfer in quaterthiophene versus integer charge transfer in $\mathrm{P} 3 \mathrm{HT} / \mathrm{F}_{4} \mathrm{TCNQ}$. (11,12) The crystallinity/morphology of the pristine polymer films prior to doping is also a key parameter 
that controls the final conductivities. In $\mathrm{F}_{4} \mathrm{TCNQ}$ vapor-phase doped films, conductivities of 12.7 S/cm are common for highly crystalline P3HT (13) versus $220 \mathrm{~S} / \mathrm{cm}$ for annealed PBTTT films. (14)

Given the high charge transport anisotropy of $\mathrm{P} 3 \mathrm{HT}$, alignment of the polymer films prior to doping is one additional and very effective method to enhance charge conductivity in doped thin films. $(15,16) \mathrm{F}_{4}$ TCNQ-doping of thin films oriented by high temperature rubbing yields highly oriented conducting polymer films with enhanced conductivities and thermopowers along the rubbing direction. (17) Transmission Electron Microscopy and polarized UV-vis-NIR spectroscopy analysis of highly oriented thin films of $F_{4}$ TCNQ-doped P3HT demonstrated that the $\mathrm{F}_{4} \mathrm{TCNQ}^{-}$anions are located in the layers of alkyl side chains within crystalline P3HT domains with the molecular long axis of $\mathrm{F}_{4} \mathrm{TCNQ}^{-}$oriented perpendicular to the polymer backbone. (17) This result raises new questions about the doping mechanism in the majority of semiconducting polymers bearing solubilizing alkyl side chains. In particular, to what extent do the packing (interdigitated or not) and the length of alkyl side chains impact the doping kinetics and ultimate doping level. This is of high importance for the design of new TE materials as the choice of alkyl side chains may help achieve well-defined doping levels and thus to tune the TE properties of doped polymer semiconductors.

The present contribution focuses on a series of poly(2,5-bis(3-alkylthiophen-2-yl)thieno[3,2b]thiophene) (PBTTT) polymers that differ by the length of their linear alkyl side chains, from n-octyl to $n$-octyldecyl $\left(\mathrm{C}_{8}, \mathrm{C}_{12}, \mathrm{C}_{14}, \mathrm{C}_{18}\right)$. PBTTT is a semi-conducting polymer that exhibits high charge carrier mobilities (up to $1 \mathrm{~cm}^{2} \cdot \mathrm{V} \cdot \mathrm{s}$ ). It has a layered structure composed of highly $\pi$-stacked backbones separated by layers of alkyl side chains. $(18,19)$ PBTTT can readily be oriented by both blade coating or high temperature rubbing. (20-23) PBTTT with dodecyl 
side chains $\left(\mathrm{C}_{12}\right.$-PBTTT) showed very high dichroic ratio of more than 10 and high anisotropy in charge mobilities in thin films rubbed at $125^{\circ} \mathrm{C} .(21)$

Since doping in $\mathrm{F}_{4} \mathrm{TCNQ} /$ Acetonitrile $(\mathrm{ACN})$ solution preserves alignment of the oriented PBTTT films, the combination of rubbing and solution doping is an effective method to prepare highly oriented conducting polymer films. This strategy is extended here to a family of PBTTTs with different alkyl side chains from $n$-octyl $\left(C_{8}\right)$ to $n$-octyldecyl $\left(C_{18}\right)$. To that aim, the doping protocol is identical for all polymers i.e. using acetonitrile as a solvent and fixing the F4TCNQ concentration to $1 \mathrm{mg} / \mathrm{ml}$. Acetonitrile has been chosen as it is an orthogonal solvent for all PBTTTs. As anticipated, all investigated PBTTTs exhibit high orientation prior to and after doping with $\mathrm{F}_{4} \mathrm{TCNQ}$. The kinetics of $\mathrm{F}_{4} \mathrm{TCNQ}$ doping in solution are measured for four PBTTTs, namely $\mathrm{C}_{8}$-PBTTT, $\mathrm{C}_{12}$-PBTTT, $\mathrm{C}_{14}$-PBTTT and $\mathrm{C}_{18}$-PBTTT. The structure of the films with maximum doping level are investigated by low dose electron diffraction and polarized UV-vis spectroscopy. Finally, the anisotropic charge transport and Seebeck coefficients are measured in the rubbed thin films. Structure-property correlations are drawn as a function of doping time and alkyl side chain length.

\section{Results.}

As demonstrated in our previous work, combining high temperature rubbing and doping of the oriented films from a solution of $\mathrm{F}_{4} \mathrm{TCNQ}$ in an orthogonal solvent such as acetonitrile affords highly oriented films of conducting polymers. The structure and charge transport properties of which are readily controlled by adjusting the dopant concentration fixed to $1 \mathrm{mg} / \mathrm{ml}$ in this study. (17) Hereafter, we show that the doping level can also be controlled via the doping time i.e. the contact time between the oriented polymer films and the solution of dopant. 
Figure 1 illustrates the high birefringence in the doped films and the change in polarized UVvis absorption for two PBTTTs with $\mathrm{C}_{12^{-}}$and $\mathrm{C}_{18^{-}}$side chains. The Polarized Optical Microscopy (POM) images show that the birefringence and thus orientation of the films is preserved after doping. Polarized UV-vis-NIR spectroscopy was performed with the light polarization either parallel or perpendicular to the rubbing direction. It evidences the presence of highly polarized signals from the polaron (P1 and P2 bands), the neutral polymer (N) and from the $\mathrm{F}_{4} \mathrm{TCNQ}^{-}$anion. The neutral and polaronic absorption bands are polarized along the rubbing direction (Figure 1.c and 1.f) contrary to the characteristic bands of the $\mathrm{F}_{4} \mathrm{TCNQ}^{-}$anions. For $\mathrm{PO} \perp \mathrm{R}$ (black curves in Figures $1 \mathrm{c}$ and d), a weak contribution from amorphous PBTTT (a) is apparent as a shoulder around $500 \mathrm{~nm}$. (21) All PBTTTs show a dominant absorption of the $\mathrm{F}_{4} \mathrm{TCNQ}^{-}$anion polarized perpendicular to the backbone of PBTTT indicating that the long axis of the $\mathrm{F}_{4} \mathrm{TCNQ}^{-}$anion is oriented essentially perpendicular to the polymer backbone. (17) For all investigated side chain lengths $\left(C_{8}\right.$ to $\left.C_{18}\right)$, the dopant molecules are hosted within the layers of alkyl side chains. The small remaining absorption of $\mathrm{F}_{4} \mathrm{TCNQ}^{-}$anions for POL//R is either due to the misoriented domains of PBTTT or to a possible small tilt of the long axis of $\mathrm{F}_{4} \mathrm{TCNQ}^{-}$anions away from the normal to the polymer backbone. 


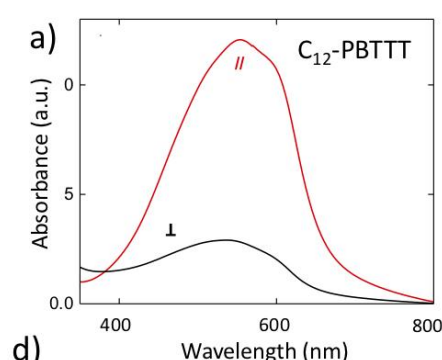

d)

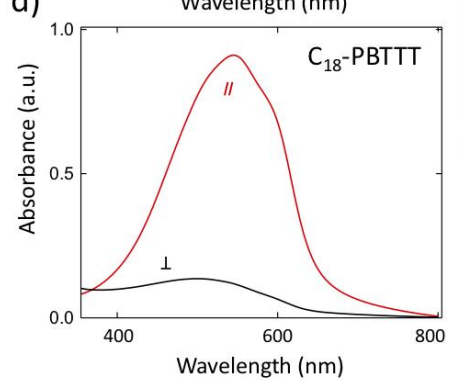

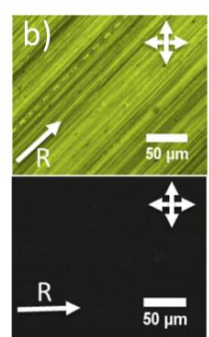

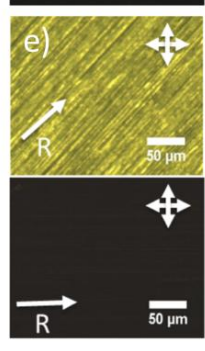

c)
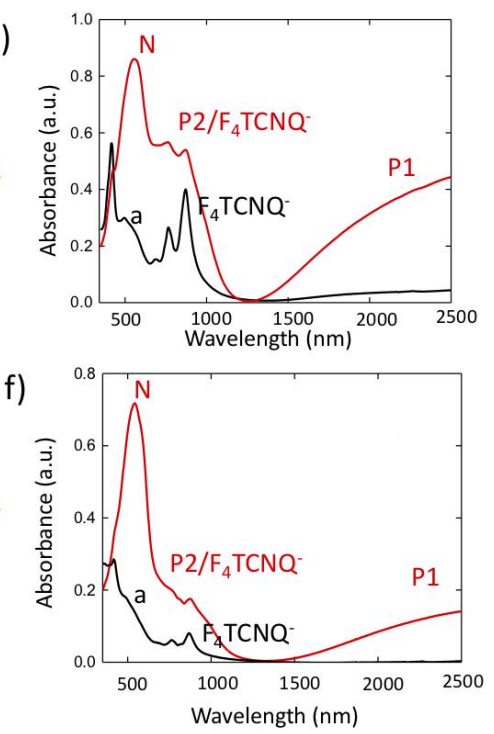

Figure 1. Example of alignment induced by high temperature rubbing $\left(T_{R}=125^{\circ} \mathrm{C}\right)$ for $C_{12}$-PBTTT and $C_{18}$-PBTTT thin films and evolution upon doping in solution with $F_{4} T C N Q / A C N(1 \mathrm{mg} / \mathrm{ml})$. (a) and (d) Polarized UV-vis spectra prior to doping. (b) and (e) POM images under crossed polarizers showing a high birefringence of the rubbed films when the films are oriented with the rubbing direction $(R)$ at $45^{\circ}$ to the polarizer and full extinction when $R$ is parallel to the polarizer. The rubbing direction is given by the arrow $R$. (c) and (f) Polarized UV-vis-NIR spectra of the doped PBTTT films at saturation, in red when the light polarization is parallel to the rubbing direction $(P O L / / R)$, in black when the light polarization is perpendicular to the rubbing direction $(P O L \perp R)$. The main spectral features are highlighted. $P 1$ and $P 2$ correspond to polaronic bands of doped PBTTT. The $F_{4} T C N Q$ bands are highlighted as well as the neutral polymer $N$ and the amorphous non oriented fraction of the polymer ' $a$ '.

Having set the basis of the orientation and doping procedures and outcome, we will successively consider in the following, the kinetics of doping, the integer charge transfer and doping level reached at saturation, the structural changes induced by doping and finally the evolution of TE properties versus side chain length.

\section{a. Kinetics of doping.}


Sequential doping of polymer semi-conductors is a complex mechanism based on the diffusion of dopants in the semi-crystalline polymer matrix coupled to a redox reaction between polymer and dopant. So far, little attention has been paid to the doping kinetics of semiconducting polymers such as PBTTT. It was mostly assumed that the doping is fast and almost instantaneous. Hereafter, UV-vis-NIR spectroscopy is used to follow the kinetics of doping versus doping time. Oriented films of various PBTTTs are doped sequentially by increasing the time of contact between the film and the dopant solution in acetonitrile $(1 \mathrm{mg} / \mathrm{ml})$. The evolution of the UV-vis spectrum in both parallel (POL//R) and perpendicular (POL $\perp R$ ) polarizations vs rubbing direction are shown in Figures 2 and 3 for four PBTTTs with different side chains, respectively.

For $\mathrm{POL} / / \mathrm{R}$, the main absorption peaks after doping correspond to the polaronic $\mathrm{P} 1$ and P2 bands with a fraction of undoped polymer $(\mathrm{N})$. For $P O L \perp R$, the spectrum is quickly dominated by the $\mathrm{F}_{4} \mathrm{TCNQ}^{-}$anion peaks $(413 \mathrm{~nm}, 770 \mathrm{~nm}$ and $875 \mathrm{~nm}$ ) beside a contribution from amorphous PBTTT that varies little with doping time. For all polymers, the absorption bands of the polaron ( $\mathrm{P} 1$ and $\mathrm{P} 2$ ) and of the $\mathrm{F}_{4} \mathrm{TCNQ}^{-}$anion increase with doping time and saturate for long doping times (>10 $\mathrm{min}$ ). The saturation indicates that a maximum doping concentration is reached for all polymers. For a very short doping time of $5 \mathrm{~s}$, the polaronic bands and anion bands are already intense for $\mathrm{C}_{12}$-PBTTT whereas for $\mathrm{C}_{18}$-PBTTT no doping is observed. In the same time interval, the absorption peak of the neutral polymer decreases substantially for $\mathrm{C}_{8^{-}}, \mathrm{C}_{12^{-}}$and $\mathrm{C}_{14^{-}}$-PBTTT whereas a smaller decrease of absorbance is evidenced in the case of $\mathrm{C}_{18}$-PBTTT. 
POL // Rubbing Direction
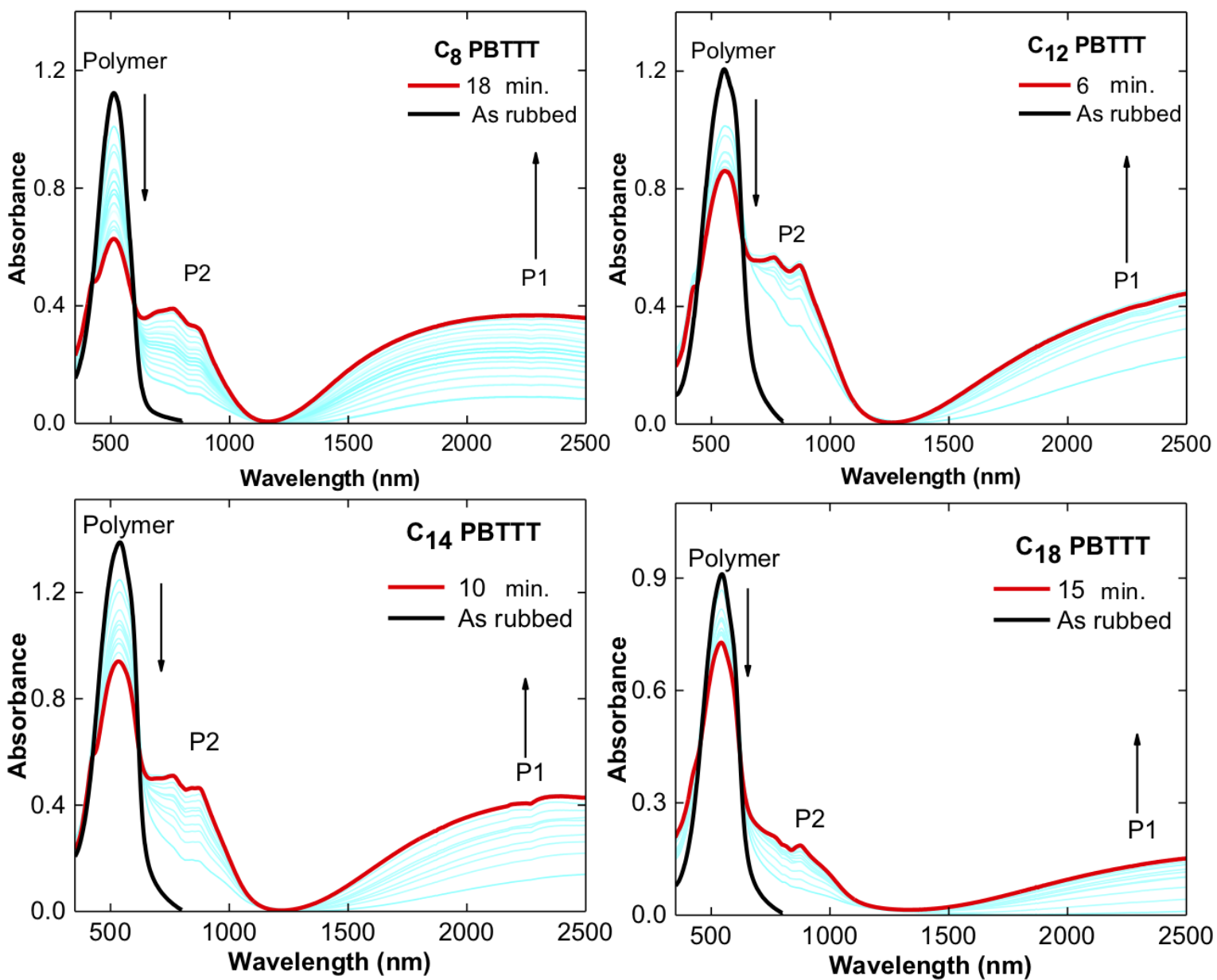

Figure 2. Kinetics of PBTTT doping with $F_{4} T C N Q$ in acetonitrile $(1 \mathrm{mg} / \mathrm{ml})$ for $P O L / / R$ as a function of side chain length. Polaronic bands are labeled P1 and P2. Note that the P2 band overlaps with a small contribution from the $F_{4} T C N Q$ anion. The spectra for the saturation of doping are highlighted in red. The absorption spectra of the undoped films are shown in black. 
$\mathrm{POL} \perp$ Rubbing Direction
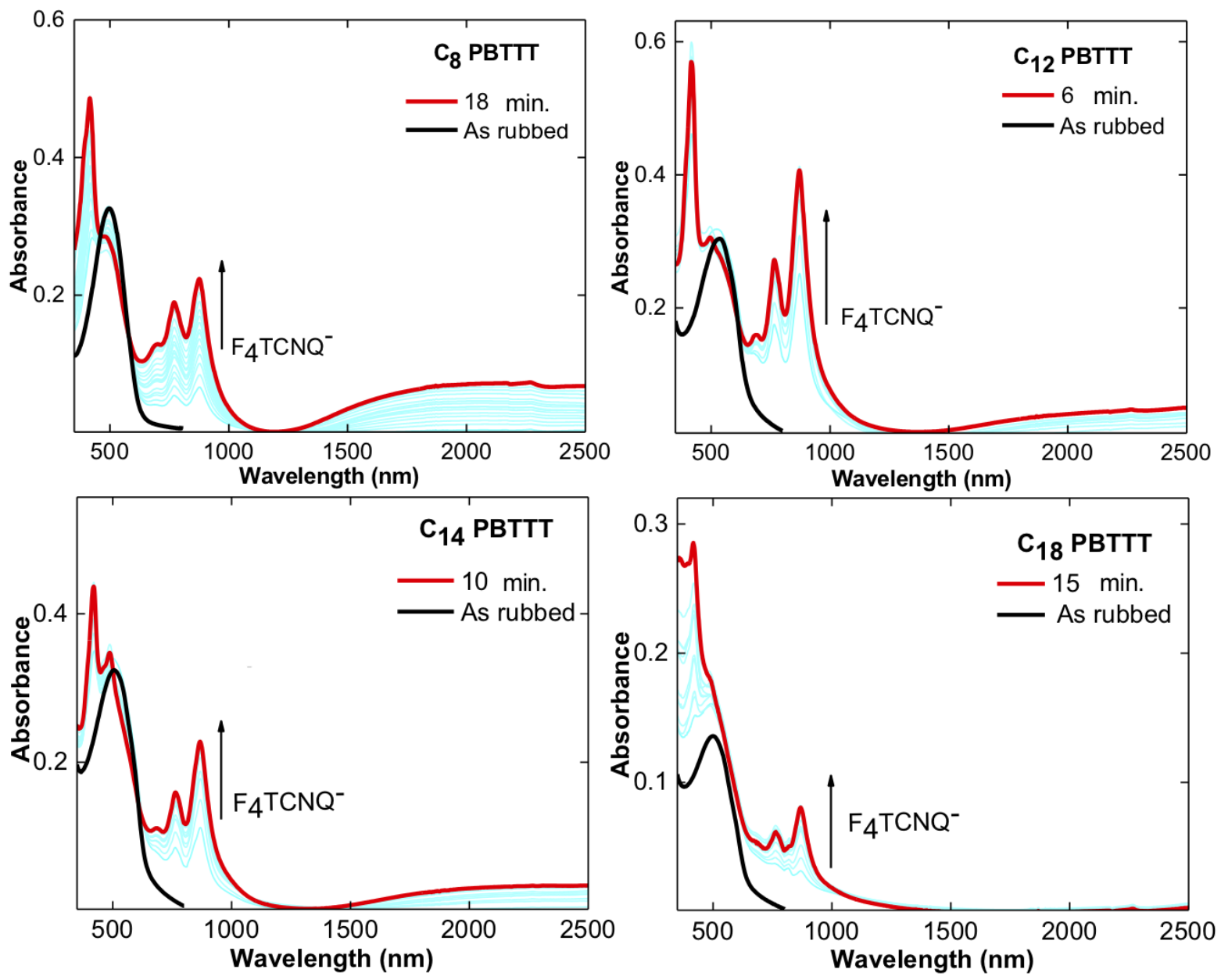

Figure 3. Kinetics of PBTTT doping with $F_{4} T C N Q$ in acetonitrile $(1 \mathrm{mg} / \mathrm{ml})$ for $P O L \perp R$ as a function of side chain length. Polaronic bands are labeled P1 and P2. The spectra after saturation of doping are highlighted in red. The absorption spectra of the undoped films are shown in black.

The peak maximum of the polaronic band P1 is around $2200 \mathrm{~nm}(0.56 \mathrm{eV})$ in $\mathrm{C}_{8}$-PBTTT but beyond $2500 \mathrm{~nm}(0.50 \mathrm{eV})$ for the other three investigated PBTTTs. Recent work by Ghosh et al. on polarons in $\mathrm{P} 3 \mathrm{HT}$ indicate that the $\mathrm{P} 1$ peak position is determined, at least in part, by the distance between the polythiophene backbone and the $\mathrm{F}_{4} \mathrm{TCNQ}^{-}$anion located in the layers of alkyl side chains. $(24,25)$ When the polaron and the anion are placed at infinite distance, the P1 band is most red-shifted. Upon increasing Coulombic interactions, the P1 band progressively shifts to higher energy. Our observation of an apparent larger P1 energy 
for $\mathrm{C}_{8}$-PBTTT is therefore consistent with a shorter polaron-anion distance in $\mathrm{C}_{8}$-PBTTT as compared to the other PBTTTs with longer side chains.

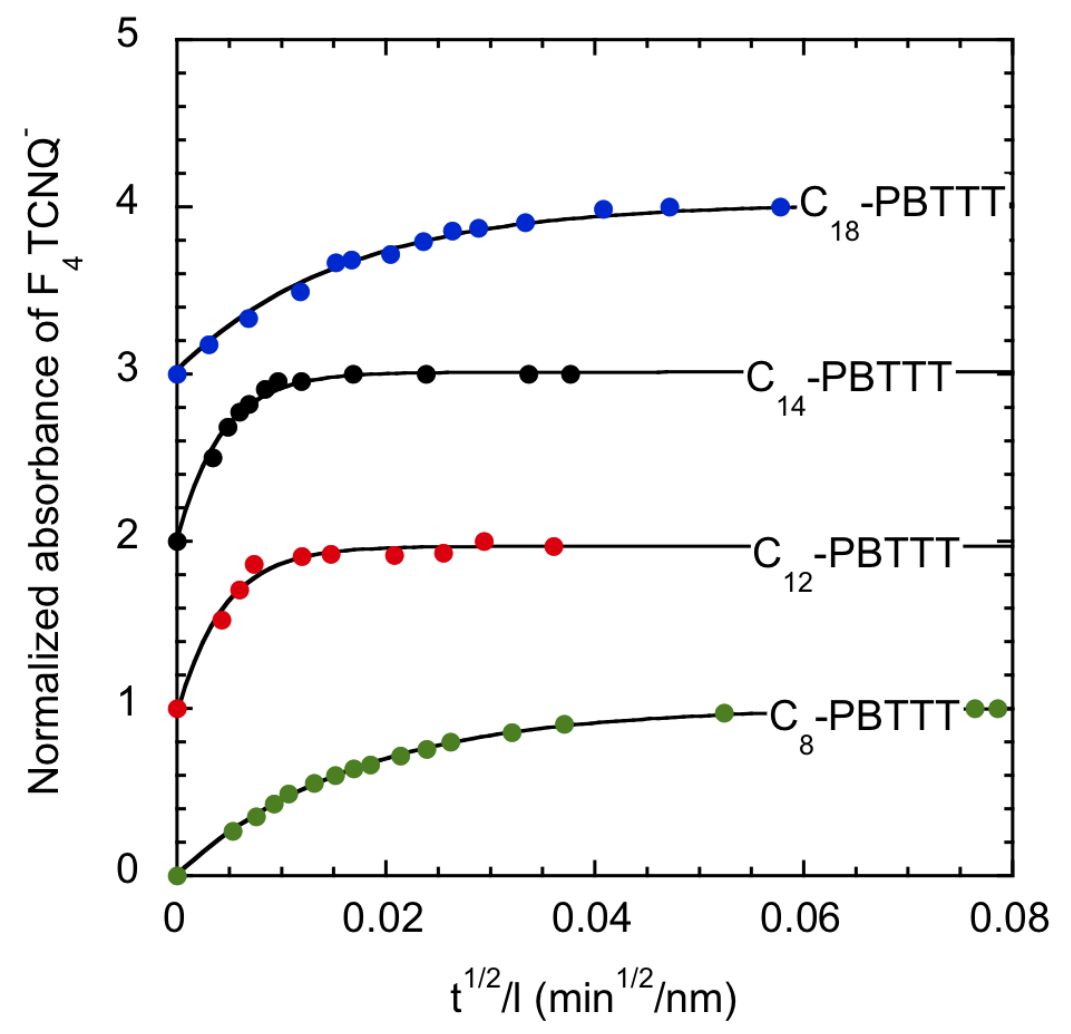

Figure 4. Doping kinetics of PBTTTs with $F_{4} T C N Q$ in acetonitrile $(1 \mathrm{mg} / \mathrm{ml})$ for various lengths of alkyl side chains as indicated by the time dependence of the $\mathrm{F}_{4} T C N Q^{-}$anion absorption peak (0-0 vibronic band in the range 870$883 \mathrm{~nm})$. For clarity, the kinetics curves are shifted along the ordinate axis. The representation against $t^{1 / 2} / /$ is independent of the nominal film thickness I and allows to extract the diffusion coefficient $D$ for each polymer (see Table 1). The continuous lines are the result of the fitting following the phenomenological equation given in the text.

A more quantitative analysis of the doping kinetics is obtained by plotting the intensity of the $\mathrm{F}_{4} \mathrm{TCNQ}^{-}$anion band at $875 \mathrm{~nm}$ as a function of time (see supporting information SI1). The absence of UV-vis signature of neutral $F_{4} T C N Q$ in the films (26) indicates that each neutral $\mathrm{F}_{4}$ TCNQ diffused into the polymer film is ionized almost instantaneously upon redox reaction in the polymer film. Accordingly, the kinetics of the 
absorbance of $\mathrm{F}_{4} \mathrm{TCNQ}^{-}$anions should reflect the diffusion of the ionized dopant in polymer matrix. For all polymers, the absorbance of the anion intensity scales like $\sqrt{ } \square$ for short doping times and it tends to saturate at long doping times. Each polymer is characterized by a typical doping time $\tau$. However, this time constant increases with film thickness (see Figure SI 2). This is related to the dependence between the characteristic doping time $\tau$ and the film thickness I. In a diffusion-limited regime: $\square=\sqrt{\square \square}$. The finite film thickness is responsible for the saturation of the doping kinetics. Accordingly, plotting the normalized $\mathrm{F}_{4} \mathrm{TCNQ}^{-}$absorption against $t^{1 / 2} / \mathrm{l}$ helps extract the diffusion coefficients of $\mathrm{F}_{4} \mathrm{TCNQ}^{-}$in the polymer matrix, D, for each PBTTT (In particular, it is possible to verify that two films with different thickness fall on a single master curve (see Figure SI 2)). (27) The time-dependence of the band intensity of the absorption peak at $875 \mathrm{~nm}, \mathrm{~A}_{875}(\mathrm{t})$, was accordingly adjusted using the phenomenological equation:

$$
\square_{875}(\square)=\square_{0}\left(1-\exp \left(-\frac{\sqrt{\square}}{\square}(\square)^{\frac{1}{2}}\right)\right)
$$

Where $A_{0}$ is the final absorbance reached at saturation, $I$ is the film thickness and $D$ is the diffusion coefficient of $\mathrm{F}_{4} \mathrm{TCNQ}^{-}$in the polymer.

As seen in Figure 4, the kinetics of doping of all polymers are very well described by equation (1). The extracted diffusion coefficients are collected in table $1 . \mathrm{C}_{12}$ - and $\mathrm{C}_{14}$-PBTTT show the highest diffusion coefficients of approx. $9 \cdot 10^{-12} \mathrm{~cm}^{2} / \mathrm{s}$ which is close to that reported by Maliakal for the diffusion of iodine into P3HT films. (28) In strong contrast, both $\mathrm{C}_{8}$-PBTTT and $\mathrm{C}_{18}$-PBTTT show significantly smaller diffusion coefficients of approx. $0.6 \cdot 10^{-12}$ $\mathrm{cm}^{2} / \mathrm{s}$.

The difference in diffusion coefficients of $\mathrm{F}_{4} \mathrm{TCNQ}^{-}$into the different PBTTTs underlines the essential role of side chain length and packing on the diffusion mechanism of 
$\mathrm{F}_{4} \mathrm{TCNQ}$ in the side chain layers. This assumption is further supported by DSC results that show well defined side chain crystallization/melting peaks for $\mathrm{C}_{18}$-PBTTT, whereas no such peaks are seen for $\mathrm{C}_{8}$-PBTTT and only broad and weak peaks for $\mathrm{C}_{12}$-PBTTT and $\mathrm{C}_{14}$-PBTTT (see supporting information, Figure S3 and Table S1). The important melting/crystallization peaks for $\mathrm{C}_{18}$-PBTTT are consistent with those observed for the corresponding poly(3alkylthiophene). (29) Accordingly, only $\mathrm{C}_{18}$-PBTTT shows evidence for a well-defined crystalline packing of side chains, contrary to the other PBTTTs. Thus, if $\mathrm{C}_{18}$ side chains are effectively packed to form a tight polymethylene sublattice, the inclusion of dopant molecules will be more difficult leading to lower doping levels and slower diffusion kinetics. The intermediate cases of $\mathrm{C}_{12^{-}}$and $\mathrm{C}_{14^{-}}$side chains seem most adapted to host the dopant molecules as the layers of side chains are only imperfectly packed. In the crystal structure of $\mathrm{C}_{14}$-PBTTT proposed by Cho et al. the area per alkyl side chain (stem) is $24 \AA^{2}$ versus $18 \AA^{2}$ for a polyethylene crystal. (30-32) This implies that there is substantial space for hosting dopant molecules in the imperfectly packed layers of $\mathrm{C}_{12^{-}}$and $\mathrm{C}_{14^{-}}$side chains. The reason why the doping kinetics is also slow for $\mathrm{C}_{8}$-PBTTT is not yet clear. However, one may suppose that the side chain layers of $\mathrm{C}_{8}$-PBTTT are too disordered so that the $\mathrm{F}_{4}$ TCNQ molecules cannot be well intercalated between alkyl side chains. This would also be consistent with the UV-visNIR results showing that the $\mathrm{F}_{4} \mathrm{TCNQ}^{-}$anions are not well oriented in the layers of side chains (anion peaks visible for both // and $\perp$ polarizations). Overall, the results on doping kinetics give strong evidence on the important role of side chain packing and length on the ultimate doping levels and doping kinetics. This is further supported by the dependence of doping level on alkyl side chain length as seen hereafter.

\section{b. Estimation of doping level and integer charge transfer.}


The oriented character of the doped PBTTT films helps to establish the saturation level of doping since the contributions of polarons and $\mathrm{F}_{4} \mathrm{TCNQ}^{-}$are dominant for light polarization parallel and perpendicular to the rubbing direction, respectively. Therefore, the concentration of $\mathrm{F}_{4} \mathrm{TCNQ}^{-}$can be more readily quantified as compared to non-oriented films for which multi-peak fitting is necessary to disentangle polaronic and $\mathrm{F}_{4} \mathrm{TCNQ}^{-}$contributions. (33) Regarding $\mathrm{F}_{4} \mathrm{TCNQ}$, the extinction coefficient $\varepsilon$ of the $0-0$ absorption at $880 \mathrm{~nm}$ is known $\left(\varepsilon=50000 \mathrm{Mol}^{-1} \mathrm{~L} \mathrm{~cm}^{-1}\right.$ ). (34) We also know the lattice parameters of the doped phases for all PBTTTs at saturation. Hence, it is possible to extract the ratio of concentrations of both $\mathrm{F}_{4} \mathrm{TCNQ}^{-}$anion and thiophene cycles in the doped films at saturation (see $\mathrm{SI}$ section for details on the determination of the doping level). The obtained values are reported in Table 1. $\mathrm{C}_{12}$-PBTTT shows the highest doping concentration of $14 \pm 3 \%$ of $\mathrm{F}_{4} \mathrm{TCNQ}^{-}$anion per thiophene cycle whereas the lowest doping level is observed for $\mathrm{C}_{18^{-}}$PBTTT (3.3\%). Both $\mathrm{C}_{14^{-}}$ PBTTT and $\mathrm{C}_{8}$-PBTTT show intermediate doping levels around $7 \%$.

On one hand, the amount of generated anion depends on the possibility of charge transfer between the PBTTT backbone and the neutral $\mathrm{F}_{4} \mathrm{TCNQ}$ molecules that have diffused inside the side chain layers. Charge transfer between PBTTT and $\mathrm{F}_{4} \mathrm{TCNQ}$ depends on the energetic difference between the donor's HOMO and the acceptor's LUMO. Cyclic-voltammetry measurements indicate that all four PBTTTs have very close HOMO levels (see Figure S4 and table S2) and therefore, the slight differences in HOMO positions cannot account on their own for the observed differences in doping levels for the PBTTTs. We observe a decrease in doping level from the $\mathrm{C}_{12^{-}}$to $\mathrm{C}_{18^{-}}$PBTTT suggesting that the length of side chain layers is one important parameter influencing the final doping level. However, $\mathrm{C}_{8}$-PBTTT shows a doping level quite similar to $\mathrm{C}_{14}$-PBTTT, which suggests that another parameter must influence the 
final doping level. As show previously for the doping kinetics, the diffusion coefficient D of $\mathrm{F}_{4} \mathrm{TCNQ}^{-}$in the layers of side chains depends also on the crystallinity/packing of the side chains. As demonstrated by DSC, the layers of alkyl side chains are particularly well and tightly packed for $\mathrm{C}_{18}$-PBTTT, which explains the slow and difficult diffusion of $\mathrm{F}_{4}$ TCNQ for this polymer, hence the low doping level. In strong contrast, the absence of crystallization/melting observed for $\mathrm{C}_{8}$-PBTTT, indicates that the disordered packing of $\mathrm{C}_{8}$ side chains is also detrimental for the diffusion and intercalation of dopant molecules.

Finally, it is also worth mentioning the potential role of the solvent used for the doping. Fujimoto et al. demonstrated that doping levels are also determined by the choice of solvents e.g. acetonitrile versus fluorinated solvents. (35) Different solvents can show different miscibilities with the polymers. In the case of acetonitrile, the miscibility in the polymer should decrease from $\mathrm{C}_{8}$ to $\mathrm{C}_{18}$-PBTTT. However, $\mathrm{C}_{8}$-PBTTT should have the highest miscibility with acetonitrile and does not show the largest doping level. In addition, the diffusion kinetics is slow in $\mathrm{C}_{8}$-PBTTT. Hence, the differences seen in doping level and kinetics with side chain length cannot be explained based on different extents of acetonitrile diffusion in the four PBTTTs.

Table 1. Characteristics of $\mathrm{F}_{4} \mathrm{TCNQ}$ doping kinetics in oriented thin films of PBTTT with various linear alkyl side chains as determined from UV-vis-NIR spectroscopy on the absorption of $\mathrm{F}_{4} \mathrm{TCNQ}^{-}$anions.

\begin{tabular}{|c|c|c|c|c|}
\hline Polymer & $\mathrm{C}_{8}$-PBTTT & $\mathrm{C}_{12}$-PBTTT & $\mathrm{C}_{14}$-PBTTT & $\mathrm{C}_{18}$-PBTTT \\
\hline Characteristic doping time & $50 \pm 5$ & $5 \pm 1$ & $8+1$ & $59 \pm 5$ \\
\hline
\end{tabular}




\begin{tabular}{|c|c|c|c|c|}
\hline$\tau(s)$ & & & & \\
\hline $\begin{array}{l}\text { Diffusion constant of } \\
\text { dopant } 10^{-12} \mathrm{~cm}^{2} \mathrm{~s}^{-1}\end{array}$ & $0.58 \pm 0.3$ & $9.0 \pm 4.5$ & $8.8 \pm 3.2$ & $0.61 \pm 0.25$ \\
\hline $\begin{array}{c}\mathrm{F}_{4} \mathrm{TCNQ}^{-} \text {anion per } \\
\text { thiophene cycle } *(\%)\end{array}$ & $7.6 \pm 2$ & $14 \pm 3$ & $6.9 \pm 2$ & $3.3 \pm 1$ \\
\hline $\begin{array}{l}\text { Highest conductivity } \\
\text { (parallel to rubbing) (S/cm) }\end{array}$ & $15 \pm 6$ & $193 \pm 30$ & $39 \pm 12$ & $6 \pm 4$ \\
\hline $\begin{array}{l}\text { Highest power factor } \\
\text { (parallel to rubbing) } \\
\left(\mu \mathrm{W} \cdot \mathrm{m}^{-2} \mathrm{~K}^{-1}\right)\end{array}$ & $2.5 \pm 0.7$ & $100 \pm 25$ & $33 \pm$ & 22 \\
\hline
\end{tabular}

* It has been estimated from the absorbance of the 0-0 vibronic band of the $\mathrm{F}_{4} \mathrm{TCNQ}^{-}$anion ( $\lambda$ in the range $873-883 \mathrm{~nm}$ ) at the saturation of the doping of oriented films doped with a solution of $1 \mathrm{mg} / \mathrm{ml}$ (see experimental section and SI for details).

It is further important to determine if the doping mechanism is typical of integer charge transfer as observed for $\mathrm{F}_{4}$ TCNQ-doped P3HT. (12) Orientation of the PBTTT films helps analyze quite precisely and independently the time dependence of polaronic and $\mathrm{F}_{4} \mathrm{TCNQ}^{-}$ bands (see Figures 2 and 3). Accordingly, it is relatively simple to identify correlations between the absorbances of the PBTTT polaron and the $\mathrm{F}_{4} \mathrm{TCNQ}$ anion as expected in case of integer charge transfer between PBTTT and $\mathrm{F}_{4} \mathrm{TCNQ}$. Figure $\mathrm{S} 5$ illustrates the correlation between the polaron and anion absorbances for all four investigated PBTTTs. All four polymers show a linear correlation between the intensities of both components, supporting integer charge transfer for all the PBTTTs. Thus, the mechanism of doping implying integer charge transfer between $\mathrm{F}_{4} \mathrm{TCNQ}$ and PBTTT is independent of the alkyl side chain length. The observed linear trends also suggest that only polaronic species and no bipolarons are generated in the range of investigated doping concentration. 


\section{c. Impact of alkyl side chain length on structure and final doping concentration.}

Low dose electron diffraction was used to investigate the structural changes upon doping for the oriented PBTTT thin films. Figure 5 collects diffraction patterns before and after doping (saturation regime) for four PBTTTs with increasing side chain length. All ED patterns are characterized by a set of equatorial (h00) $(h=1,2,3,4)$ and a meridional 003 reflection indicating that they are mostly made of face-on domains. (20) A minority of edgeon domains is also present as indicated by the weak equatorial 020 reflection. For all polymers, ED confirms the previous UV-vis-NIR and POM observations: doping in $\mathrm{F}_{4} \mathrm{TCNQ}$ acetonitrile preserves the alignment and the original orientation of PBTTT crystals observed in the rubbed films. In particular, the intensity of the meridional (003) reflection along the PBTTT backbone direction is preserved upon doping for all four polymers without important in-plane broadening. This is consistent with previous observations on P3HT oriented films. (17) Importantly, the relative intensity of 100 and 020 reflection associated to face-on vs edge-on oriented domains is not modified upon doping indicating no reorientation of crystal contact plane. Second, as observed in our previous study for $\mathrm{P} 3 \mathrm{HT}$, the inter-layer spacing $d_{100}$ shows a sizable variation upon increasing doping time for $C_{8^{-}}, C_{12^{-}}$and $C_{14^{-}}$PBTTT. The equatorial section profiles of the ED patterns help visualize the kinetics of the structural change (Figure S6) while the dependence of the interlayer spacing $d_{100}$ and of the $\pi$-stacking distance $d_{020}$ with doping time are shown in Figure 6. 


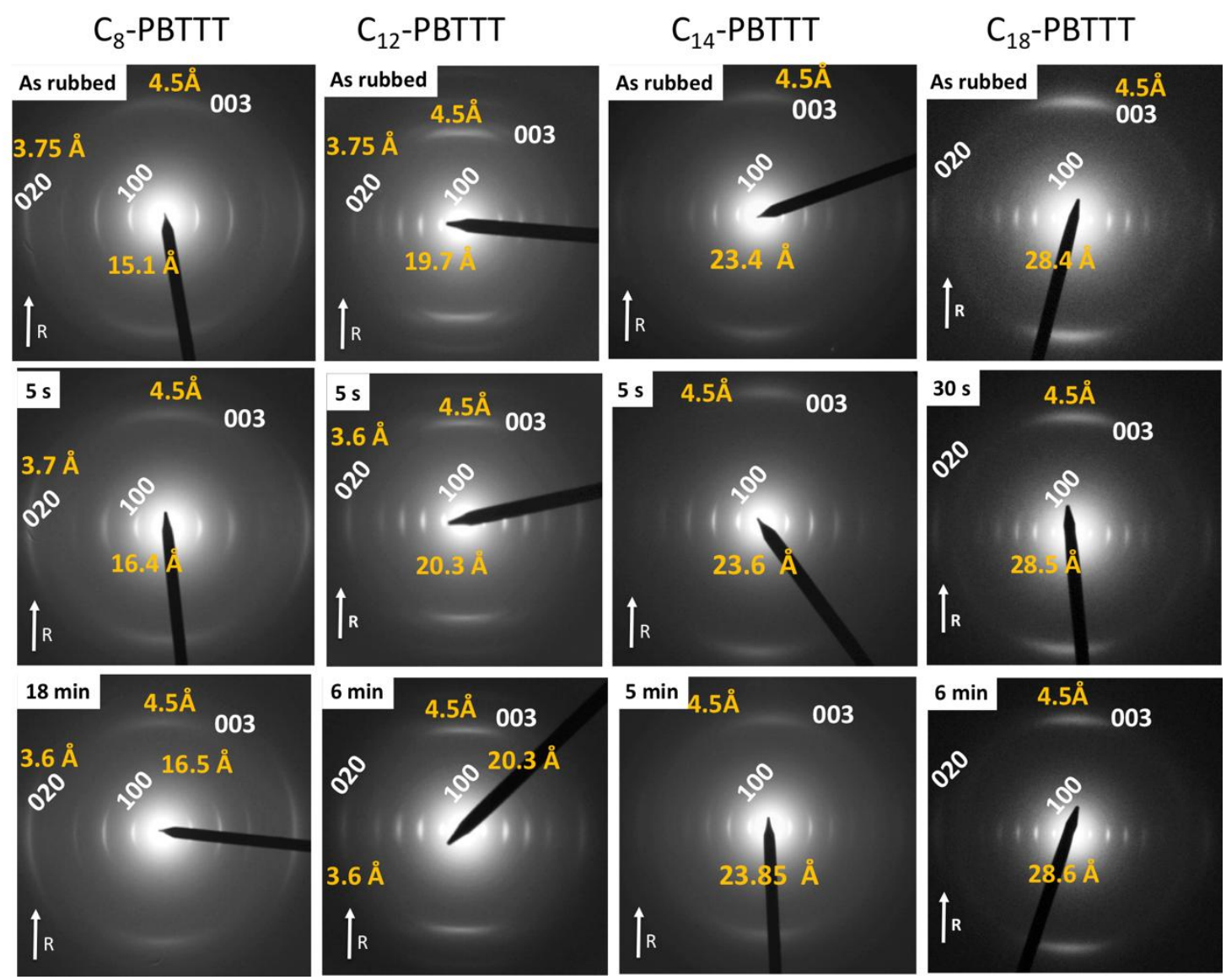

Figure 5. Evolution of the electron diffraction patterns of oriented thin films of various PBTTTs in as-rubbed films $\left(T_{R}=125^{\circ} \mathrm{C}\right)$ and after doping with $F_{4} T C N Q$ at different doping times. The reticular distances for the interlayer spacing $d_{100}$ and for the $\pi$-stacking period 020 are given in orange. The arrow $R$ indicates the chain direction induced upon rubbing. 

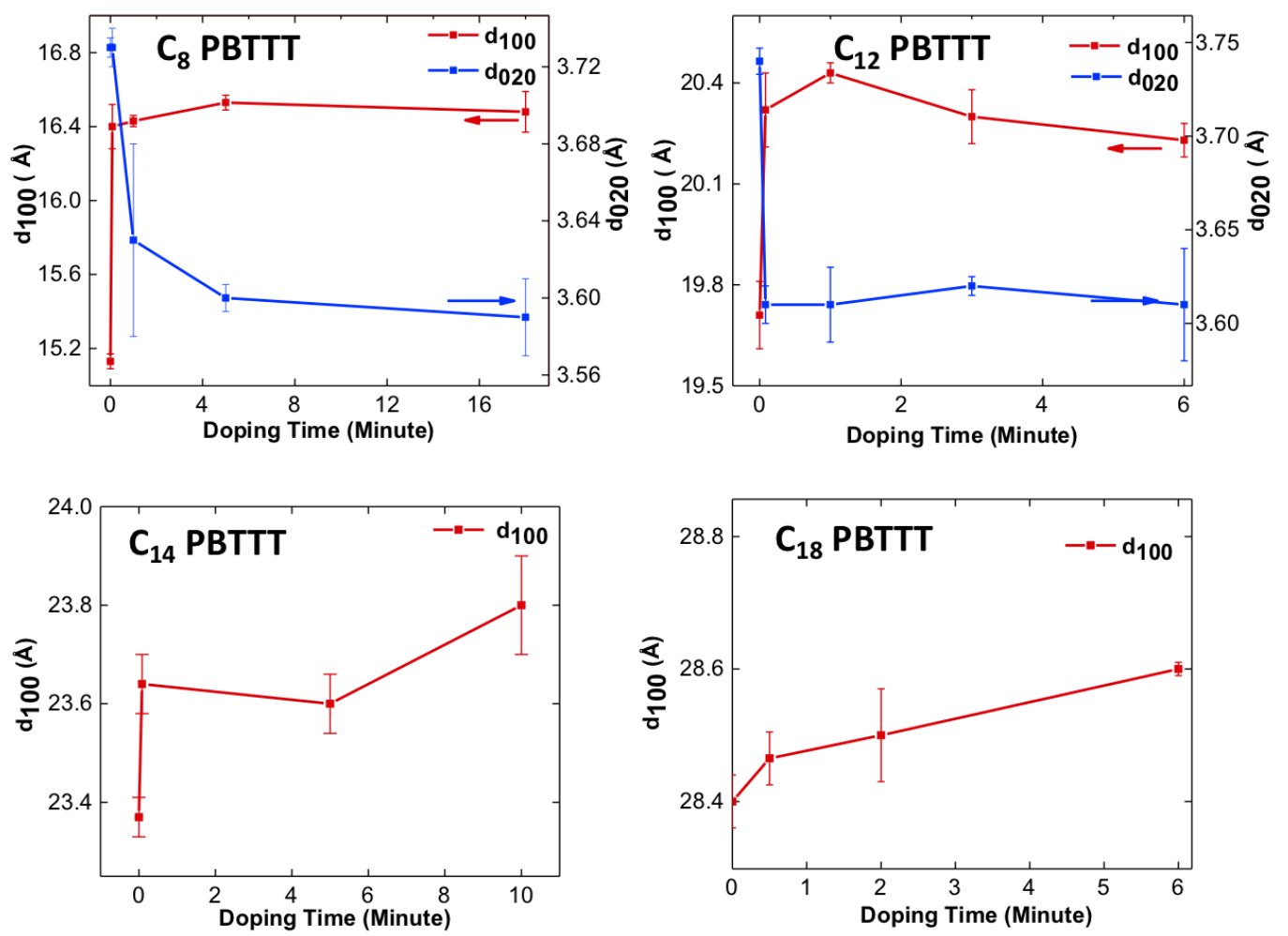

Figure 6. Kinetics of the structural changes associated to the interlayer spacing $d_{100}$ and to the $\pi$-stacking $d_{020}$ observed upon doping of the PBTTT thin films in a solution of $F_{4} T C N Q$ in acetonitrile for different side chain lengths.

For $\mathrm{C}_{12}$-PBTTT and $\mathrm{C}_{14}$-PBTTT the changes in unit cell parameters occur within a few seconds and saturation of the unit cell parameters is observed after $1 \mathrm{~min}$ of doping, in agreement with the kinetics of doping evidenced by UV-vis spectroscopy. For $\mathrm{C}_{8}$-PBTTT, the evolution of the unit cell parameters is slower and similar to that observed in UV-vis-NIR spectroscopy. More generally, for all PBTTTs the kinetics of the structural changes observed by TEM agree with the doping kinetics evidenced by UV-vis spectroscopy. More precisely, for $\mathrm{C}_{8}$-PBTTT, a clear expansion of the interlayer spacing is observed from $15.1 \AA$ to $16.4 \AA$ and a contraction of $\pi$-stacking from $3.75 \AA$ to $3.60 \AA$. Importantly, for $t \geq 1 \mathrm{~min}$, there is no coexistence of doped and undoped phase: only one 100 reflection corresponding to the doped phase is observed. This is similar to previous observations for $\mathrm{F}_{4}$ TCNQ-doped P3HT 
and indicates that the remaining absorbance of neutral $\mathrm{C}_{8}$-PBTTT seen in the UV-vis spectrum must correspond to non-doped chain segments enclosed inside the crystals of the doped phase and not to chains within undoped PBTTT crystals. (16) In this regard, the doping of PBTTT with $\mathrm{F}_{4}$ TCNQ is clearly different from the co-crystallization of PBTTT and PCBM that shows the coexistence of the pure PBTTT and the co-crystal phases. (30)

For $\mathrm{C}_{12}$-PBTTT, expansion of the interlayer spacing is from $19.6 \AA$ to $20.4 \AA$ whereas the $\pi$-stacking periodicity decreases from $3.75 \AA$ to $3.60 \AA$. The situation is different for $\mathrm{C}_{18}$-PBTTT that shows a marginal interlayer spacing variation from $28.4 \AA$ to $28.6 \AA$ (see Figure 6 ). In other words, the shorter the alkyl side chains, the larger the variation of the unit cell parameters upon doping.

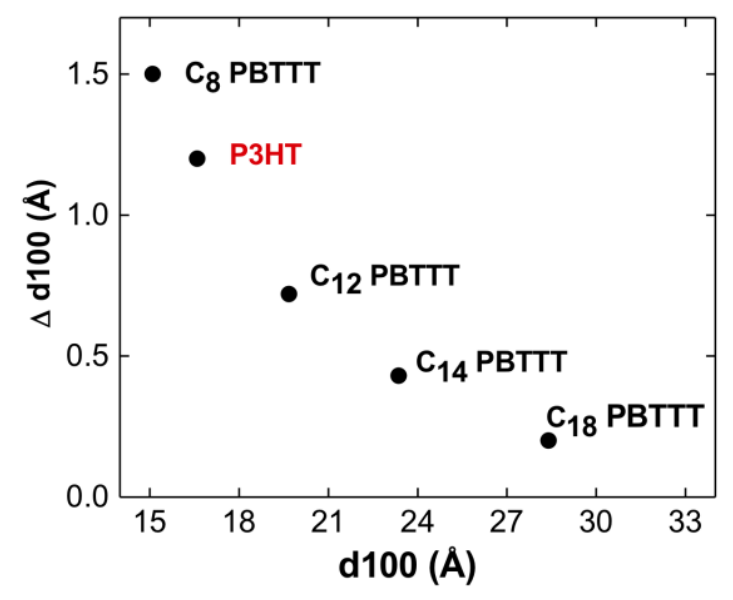

Figure 7. Dependence of the interlayer spacing variation $\Delta d_{100}$ as a function of the original interlayer spacing $d_{100}$ for PBTTTS ( $C_{8^{-}}$to $C_{18^{-}}$PBTTT). The data for $F_{4} T C N Q$-doped P3HT is taken from ref. 17

As seen in Figure 7, it is possible to correlate the variation in interlayer spacing at doping saturation $\Delta \mathrm{d}_{100}$ with the original interlayer spacing of the pristine undoped PBTTT. Basically, we observe that the polymers with small interlayer spacings show the largest variation in unit cell parameter after doping. Taking the two extreme cases, $\Delta \mathrm{d}_{100}=1.5 \AA$ for $\mathrm{C}_{8}$-PBTTT, whereas $\Delta \mathrm{d}_{100}=0.2 \AA$ for $\mathrm{C}_{18}$-PBTTT. The length of alkyl side chains does impact the final 
structural modification after doping. Most interestingly, P3HT also follows the trend of PBTTTs evidenced herein, even though it has shorter and non-interdigitated $C_{6}$ side chains. This trend might be general and valid for other semiconducting polymers.

The origin of the correlation between $\Delta \mathrm{d}_{100}$ and $\mathrm{d}_{100}$ can be rationalized based on the doping level at saturation versus side chain length. Indeed, as shown previously, the doping level at saturation is largest for $\mathrm{C}_{8}$-PBTTT i.e. the polymer showing the largest variation $\Delta \mathrm{d}_{100}$. Following the same logics, the lowest doping level of $17 \%$ is found for $\mathrm{C}_{18}$-PBTTT i.e. the polymer showing a marginal change in interlayer $d_{100}$ and $\pi$-stacking period $d_{020}$. Accordingly, the change in unit cell observed in the series of PBTTTs which reflects the final doping level at saturation, is a function of side chain length. Figure 8.b shows that the unit cell variation does indeed correlate with the doping level at saturation. This study shows accordingly, that the final crystal structure of the $\mathrm{F}_{4}$ TCNQ-doped state in PBTTT films is determined by the length of alkyl side chains.

\section{d. Anisotropy of TE properties.}

Doping oriented thin films of $\mathrm{P} 3 \mathrm{HT}$ with $\mathrm{F}_{4} \mathrm{TCNQ}$ induces a substantial increase in power factors because both charge conductivity and thermopower are enhanced in the alignment direction. (17) In order to evaluate the benefits of alignment on the TE efficiency of doped PBTTTs, we have measured the evolution in charge conductivity and Seebeck coefficients of films subjected to different doping times in a solution of $F_{4} T C N Q / A C N$. Figure 8 illustrates the values of charge conductivity $\left(\sigma_{/ /}\right.$and $\left.\sigma_{\perp}\right)$, Seebeck coefficients $\left(S_{/ /}\right.$and $\left.S_{\perp}\right)$ and the resulting power factors $\mathrm{PF}=\sigma \mathrm{S}^{2}$ for $\mathrm{C}_{12}$-PBTTT that shows the best TE performances. The 
corresponding results for the other PBTTTs are show in Figure S7-S10 of the supporting information.

The highest conductivities measured for the four polymers, follow the sequence: $C_{12^{-}}$ PBTTT $>\mathrm{C}_{14}$-PBTTT $>\mathrm{C}_{8}$-PBTTT $>\mathrm{C}_{18}$-PBTTT. The best value of $\sigma_{/ /}$is $193 \mathrm{~S} / \mathrm{cm}$ for $\mathrm{C}_{12}$-PBTTT. This value is much larger than for non-oriented $\mathrm{C}_{12}$-PBTTT and comparable to that for nonoriented vapor-phase doped PBTTT. $(14,36,37)$ For $\mathrm{C}_{12}$-PBTTT, the conductivity values tend to saturate very rapidly since the doping kinetics is very fast. The fact that $\mathrm{C}_{12}$-PBTTT reaches the highest conductivity is also consistent with the fact that this polymer shows the highest doping level as determined from the absorbance of the $\mathrm{F}_{4} \mathrm{TCNQ}^{-}$anion (see Table 1 ). The lowest conductivities are observed for $\mathrm{C}_{18}$-PBTTT with the longest side chains $\left(\sigma_{/ /}\right.$of a few $\mathrm{S} / \mathrm{cm})$, which is consistent with the fact that it has the smallest doping level at saturation (3.3\%). The polymers $\mathrm{C}_{14}$-PBTTT and $\mathrm{C}_{8}$-PBTTT show intermediate doping levels around $7 \%$ and their conductivity $\sigma_{/ /}$lies in the $15-40 \mathrm{~S} / \mathrm{cm}$ range. The relatively low conductivity of $\mathrm{C}_{8^{-}}$ PBTTT may have different origins. First, this polymer shows the most blue-shifted polaronic bands, suggesting stronger polaron localization due to stronger Coulombic interactions between the polaron and the $\mathrm{F}_{4} \mathrm{TCNQ}^{-}$anions. $(24,25)$ Second, $\mathrm{C}_{8}$-PBTTT has a relatively low molecular weight. It is known that molecular weight significantly impacts structure and morphology thus the charge mobility in polymer semiconductors. (38) As a matter of fact, $\mathrm{C}_{8}$-PBTTT is the only investigated polymer that shows clearly a semi-crystalline lamellar morphology with a $22 \mathrm{~nm}$ periodicity much alike P3HT (see supporting Figure S10). (17)

Analyzing the ratio $\sigma_{/ /} / \sigma_{\perp}$ for the four polymers helps identify the impact of side chain length on the charge transport anisotropy (see Figure 9). In the direction perpendicular to the rubbing, the highest values of $\sigma_{\perp}$ are close to $35 \mathrm{~S} / \mathrm{cm}$ for $\mathrm{C}_{12}$-PBTTT which results in 
anisotropies $\sigma_{/ / /} \sigma_{\perp}$ in the range $5-6$. For $\mathrm{C}_{8}$-PBTTT, the anisotropy is close to 2 . It is much larger for $\mathrm{C}_{18}$-PBTTT (typically 16-18). The trend in the charge transport anisotropy $\sigma_{/ / /} \sigma_{\perp}$ versus length of side chain is clear (see Figure 9.b): the longer the side chains, the larger the anisotropy $\sigma_{/ /} / \sigma_{\perp}$. This is consistent with the fact that the rubbed films consist mainly of aligned face-on oriented crystals (see ED patterns in Figure 5). In other words, charge transport measured perpendicular to the rubbing should be dominated by transport along the insulating alkyl side chains, which should be lowest for $\mathrm{C}_{18}$-PBTTT.

The Seebeck coefficients of all samples exhibit an important anisotropy in oriented thin films. The thermopower parallel to the rubbing $S_{/ /}$is always larger than perpendicular to the rubbing $S_{\perp}$. Anisotropy of Seebeck coefficient in oriented conducting polymers has been reported previously for doped polyacetylene (PA) and polyaniline. (39-41) In lodine-doped $\mathrm{PA}$, the anisotropy $\mathrm{S}_{/ /} / \mathrm{S}_{\perp}$ was of the order of two whereas the anisotropy of conductivity $\sigma_{/ /} / \sigma_{\perp}$ was in the range 50-100. Kaiser as well as Pukaci et al. proposed that the anisotropy of Seebeck coefficient is related to the heterogenous nature of the films where both metallic and semi-conducting domains coexist. This interpretation would also apply in the present case since the UV-vis spectra of all doped films show the coexistence of doped (metal-like) and undoped (semi-conducting) domains in the thin films (see Figure 2 and 3). It can be anticipated that such a co-existence of doped and undoped phases could be beneficial in oriented films to observe simultaneously a high charge conductivity and a high Seebeck coefficient. 
For $\mathrm{C}_{12}-\mathrm{PBTTT}, \mathrm{S}_{\perp}$ is close to the value of the non-oriented films $(35 \mu \mathrm{V} / \mathrm{K})$ whereas $\mathrm{S}_{/ /}$is two to three times larger and can reach values of $77 \mu \mathrm{V} / \mathrm{K}$ for conductivities of $193 \mathrm{~S} / \mathrm{cm}$ (doping time $=1 \mathrm{~min}$.$) . The \mathrm{C}_{8}$-PBTTT has the lowest anisotropy (1.4-2.6) whereas $C_{18}$ has the highest one (3-4.1). The anisotropy in Seebeck coefficient parallels that of the charge conductivity. However, as already noted for rubbed films of P3HT doped with $\mathrm{F}_{4} \mathrm{TCNQ}$, the anisotropy of $\mathrm{S}$ is always lower than that of the charge conductivity $\sigma$. (17) The dependence of $S_{/ /}$with doping time parallels the kinetics of doping evidenced by UV-vis spectroscopy versus side chain length. Both $\mathrm{C}_{8}$-PBTTT and $\mathrm{C}_{18}$-PBTTT have the slowest doping kinetics. Hence the Seebeck coefficients observed at low doping times are particularly high, especially for $\mathrm{C}_{18^{-}}$ PBTTT with $\mathrm{S}_{/ /}>400 \mu \mathrm{V} / \mathrm{K}$ for $\mathrm{t}=5 \mathrm{~s}$. Conversely, for $\mathrm{C}_{12}$-PBTTT and its fast doping kinetics, the variation of $\mathrm{S}$ with doping time is limited.

a)

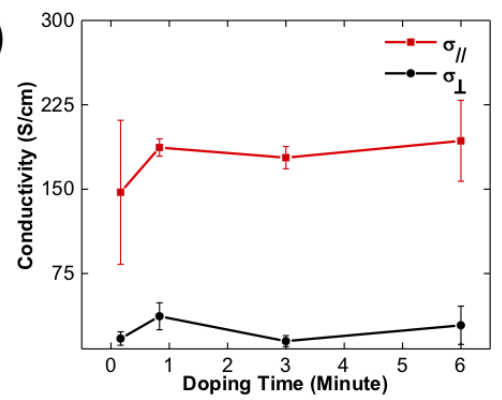

b)

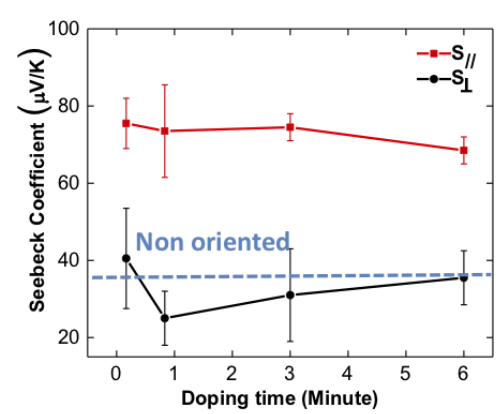

c)

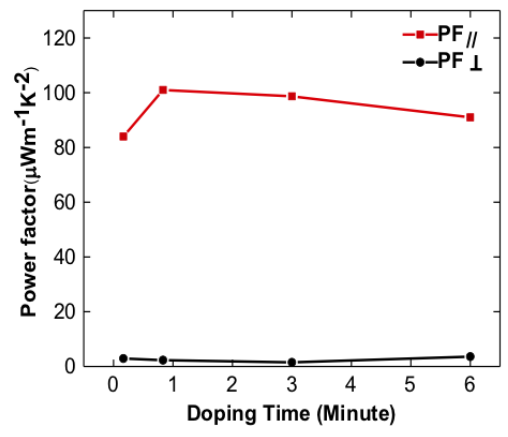


Figure 8. Evolution of the charge conductivity, Seebeck coefficient and power factor as a function of increasing doping concentration of $F_{4}$ TCNQ for oriented thin films of $C_{12}$-PBTTT. All values are measured along the directions parallel (//) and perpendicular $(\perp)$ to the rubbing.
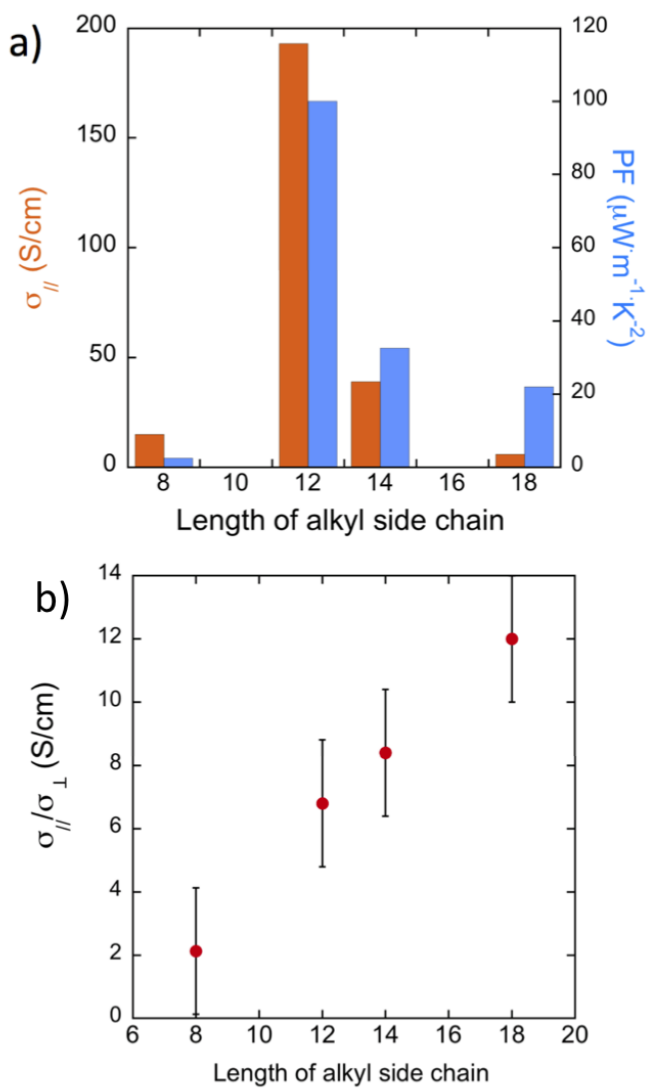

Figure 9. Evolution of the maximum conductivity $\left(\sigma_{/ /}\right)$and power factor (PF) along the rubbing direction (a) and of the average charge conductivity anisotropy $\sigma_{/ /} / \sigma_{\perp}(b)$ versus side chain length in $F_{4}$ TCNQ-doped PBTTT films oriented by high temperature rubbing.

The simultaneous increase of charge conductivity $\sigma_{/ /}$and thermopower $S_{/ /}$along the rubbing direction results in a substantial increase of power factors $\mathrm{PF}=\mathrm{S}^{2} \sigma$ along the rubbing direction. As seen in Figure 8 for $\mathrm{C}_{12}$-PBTTT, the values of PF are substantially enhanced along the rubbing direction and the anisotropies can be very high. They reach 66 for $\mathrm{C}_{12^{-}}$ 
PBTTT and 320 for $\mathrm{C}_{18}$-PBTTT. The maximum PF for the $\mathrm{C}_{8}$-PBTTT, $\mathrm{C}_{14^{-}}$PBTTT and the $\mathrm{C}_{18^{-}}$ PBTTT are $2.4 \mu \mathrm{W} \cdot \mathrm{m}^{-1} \cdot \mathrm{K}^{-2}, 32.6 \mu \mathrm{W} \cdot \mathrm{m}^{-1} \cdot \mathrm{K}^{-2}$ and $20.6 \mu \mathrm{W} \cdot \mathrm{m}^{-1} \cdot \mathrm{K}^{-2}$, respectively. However, $\mathrm{C}_{12^{-}}$ PBTTT surpasses the three other polymers, with power factors of the order of $100 \mu \mathrm{W} \cdot \mathrm{m}^{-2} \mathrm{~K}^{-1}$ that are comparable to those observed for vapor-phase doped PBTTT. $(36,37)$ For C $_{12}$-PBTTT and $\mathrm{C}_{18}$-PBTTT, the PF shows an optimum versus doping time and tends to decrease slightly at long doping times, when the doping level increases beyond a critical concentration. This trend is well known in many systems such as PEDOT-Tos. (4)

\section{Conclusion}

The influence of alkyl side chain length on the $\mathrm{F}_{4}$ TCNQ-doping mechanism of a series of PBTTTs was investigated from various points of view including structural variation, UV-VisNIR spectroscopic and thermoelectric properties. UV-Vis-NIR spectroscopy and DSC evidences the key role of side chain length and packing on the doping mechanism and helped determine the dopant diffusion coefficients and doping levels at saturation. Both, disordered $\mathrm{C}_{8}$ and crystalline $\mathrm{C}_{18}$ side chain layers hamper efficient dopant diffusion in the polymer films whereas loosely packed side chain layers of $\mathrm{C}_{12^{-}}$and $\mathrm{C}_{14}$-PBTTT allow for fast dopant diffusion. The observed charge conductivity of the oriented PBTTT films correlates well with the doping level at saturation: an optimum in TE properties is observed for $C_{12^{-}}$ PBTTT films. For all PBTTTs, alignment enhances substantially the TE performances by increasing simultaneously the charge conductivity and the thermopower along the chain direction. Aligned films of $\mathrm{C}_{12}$-PBTTT show charge conductivities of $193 \mathrm{~S} / \mathrm{cm}$ along the rubbing direction and power factors of approx. $100 \mu \mathrm{W} \cdot \mathrm{m}^{-2} \cdot \mathrm{K}^{-1}$. More generally, this study underlines the importance to perform a controlled crystallization and orientation of the polymer semiconductors prior to doping from solution in order to enhance their TE 
properties. On-going studies indicate that the same trends observed for solution-doped PBTTTs are also valid when doping from the vapor phase.

\section{Experimental section.}

\section{1) Polymers syntheses and characterization.}

$\mathrm{C}_{8}$-PBTTT, $\mathrm{C}_{12}$-PBTTT, $\mathrm{C}_{14}$-PBTTT, and $\mathrm{C}_{18}$-PBTTT were synthesized following the detailed procedure described in the supporting information. The macromolecular parameters are collected in Table 2. 2,3,5,5-tetrafluoro(tetracyanoquinodimethane) ( $F_{4} T C N Q$ ) was purchased from $\mathrm{TCl}$ and solvents such as anhydrous acetonitrile and ortho-dichlorobenzene were obtained from Aldrich. All the chemicals were used as received.

Table 2. Macromolecular parameters of the semiconducting polymers used in this study. (Gel permeation chromatography was performed in hot trichlorobenzene versus PS standard)

\begin{tabular}{|c|c|c|c|}
\hline Polymer & $\mathrm{M}_{\mathrm{n}}(\mathrm{g} / \mathrm{mol})$ & $\mathrm{M}_{\mathrm{w}}(\mathrm{g} / \mathrm{mol})$ & PDI \\
\hline $\mathrm{C}_{8}$-PBTTT & 13000 & 24000 & 1.84 \\
\hline $\mathrm{C}_{12}$-PBTTT & 26000 & 45000 & 1.73 \\
\hline $\mathrm{C}_{14}$-PBTTT & 17000 & 51000 & 1.64 \\
\hline $\mathrm{C}_{18}$-PBTTT & 31000 & 51000 & 3 \\
\hline
\end{tabular}

\section{2) Orientation and doping of thin films.}

The preparation of oriented PBTTT films by high-temperature rubbing followed the protocol described in previous publications. $(16,17)$ Thin films of PBTTT were prepared by doctor 
blading from a hot solution of $10 \mathrm{mg} / \mathrm{ml}$ PBTTT in ortho-dichlorobenzene (oDCB) on a glass substrate at $160^{\circ} \mathrm{C}$. Oriented polymer films were prepared by using a homemade set up consisting of a translating hot plate on which the sample is fixed and a rotating cylinder covered with a microfiber cloth. The films were rubbed at different rubbing temperatures depending on the polymer $\left(125^{\circ} \mathrm{C}\right.$ for $\mathrm{C}_{8}$-PBTTT, $\mathrm{C}_{12}$-PBTTT, $\mathrm{C}_{18^{-}}$-PBTTT, and $100^{\circ} \mathrm{C}$ for $\mathrm{C}_{14^{-}}$ PBTTT). To determine the film thickness after rubbing, the films were melt-annealed to randomize the in-plane chain direction and the thickness was extracted from the UV-vis absorbance.

\section{3) Doping protocol.}

All doping experiments were carried out in a glove box (Jacomex) with $\mathrm{P}_{\mathrm{O} 2}<1 \mathrm{ppm}$ and $\mathrm{P}_{\mathrm{H} 2 \mathrm{O}}<1 \mathrm{ppm}$. All films were doped with a solution of $(1 \mathrm{mg} / \mathrm{ml}) \mathrm{F}_{4} \mathrm{TCNQ}$ prepared by dissolving $\mathrm{F}_{4} \mathrm{TCNQ}$ in anhydrous acetonitrile in a glass vial. Doping was done by dipping the oriented polymer film in the dopant solution for the different time intervals.

\section{3) Thin film characterization.}

Structural analysis: TEM: Samples for transmission electron microscopy was prepared by spin coating $(3000 \mathrm{rpm})$ a thin layer of NaPSS $(10 \mathrm{mg} / \mathrm{ml} \mathrm{aq})$ on a precleaned glass substrate and this substrate was used for the preparation of oriented polymer film as described above. Doping was done by dipping the oriented polymer film in the dopant solution for the different time interval and subsequently removed from the glass substrate by floating in the distilled water and recovered on a TEM copper grid. TEM was performed in the bright field and diffraction modes using a CM12 Philips microscope equipped with an MVIII (Soft Imaging System) Charge Coupled Device camera. Beam exposure was set to a minimum using the low dose system to avoid de-doping under the electron beam that is observed 
when the same zone is exposed for a prolonged period of time. Scanning Electron Microscopy observations were performed at $1 \mathrm{kV}$ with a HITACHI SU8010 FEG-SEM on asprepared film (no coating) to verify the uniformity of the rubbed layers (see Figure SI11).

Polarized UV-Vis-NIR absorption: The orientation of the polymer films was probed by UV-VisNIR absorption (350-2500 nm) using a Cary 5000 spectrometer with polarized incident light and spectral resolution of $1 \mathrm{~nm}$. The UV-Vis-NIR spectra of the doped polymer film were measured along the parallel and perpendicular to the direction of rubbing.

Differential Scanning Calorimetry: DSC measurements were performed on a DSC Q2000 from TA Instruments under nitrogen atmosphere using a sample mass in the range 1.5-2.5 $\mathrm{mg}$. The samples were heated to $250^{\circ} \mathrm{C}$ with a heating rate of $10^{\circ} \mathrm{C} \cdot \mathrm{min}^{-1}$, then cooled to $20^{\circ} \mathrm{C}$ at $5^{\circ} \mathrm{C} \cdot \mathrm{min}^{-1}$.

Cyclic Voltametry. Oxidation potentials were determined by cyclic voltammetry with a conventional 3-electrode system using a voltammetric analyzer equipped with a platinum micro disk $\left(2 \mathrm{~mm}^{2}\right)$ working electrode and a platinum wire counter electrode. The reference electrode is constituted of a non-aqueous silver electrode including the following electrolyte solution: $0.01 \mathrm{M}$ silver nitrate $+0.1 \mathrm{M}$ Tetrabutylammonium perchlorate in Acetonitrile. Potentials were calibrated versus the saturated calomel electrode (SCE), using the ferrocene/ferrocinium $\left(\mathrm{Fc} / \mathrm{Fc}^{+}\right)$couple as an internal reference and a conventional scan rate of $100 \mathrm{mV} / \mathrm{s}$. Recrystallized tetrabutylammonium hexafluorophosphate $\left(\mathrm{Bu}_{4} \mathrm{NPF}_{6}\right)$ was used as the supporting electrolyte $(0.1 \mathrm{M})$ in distilled and anhydrous acetonitrile (ACN). All potentials are referred to the SCE electrode that was calibrated at $0.41 \mathrm{~V}$ vs Fc/Fc ${ }^{+}$system. Following the work of Jenekhe et al., we estimated the ionization potential (IP) or highest occupied molecular orbital (HOMO) from the redox data. The HOMO levels were calculated 
from the following equations, using the oxidation and reduction onset potentials: HOMO $(\mathrm{eV})=-\left[\mathrm{E}_{\text {onset }} \mathrm{Ox}(\mathrm{vS} \mathrm{SCE})+4.4\right]$, based on an SCE energy level of $4.4 \mathrm{eV}$ relative to the vacuum.

\section{4) Electrical conductivity and thermopower measurements.}

All devices were fabricated on glass substrates, cleaned by ultrasonication in acetone, ethanol, hellmanex, deionized water, and isopropanol. The cleaned substrates were dried under nitrogen prior to use. Gold electrical contacts (40 nm thick) in a four-point probe geometry ( $1 \mathrm{~mm}$ spacing between electrodes, $5 \mathrm{~mm}$ length) were deposited via controlled thermal evaporation through a shadow mask, at an average rate of 4-6 $\AA$ /s. The first layer of Chromium ( $2.5 \mathrm{~nm}$ thick) was deposited prior the gold to promote a good adhesion on the glass substrates (evaporation rate $0.5-1 \AA$ / s). The contact geometry used for the electrical conductivity and thermopower measurements is shown in Figure S2 of reference 17. On the same substrate, two devices are oriented along the rubbing direction (black) and two others in the perpendicular direction (red), which allows us to determine the charge transport and thermoelectric anisotropy on the same substrate.

Four-point-probe measurements of electrical conductivity were performed using a Keithley 4200 -SCS and a Lab Assistant Semiprobe station in a Jacomex glovebox under $\mathrm{N}_{2}$ atmosphere. To derive the resistivity $\rho$ from the sheet resistance $R$ measured on the device geometry given in Figure S3 of reference 17, we have first determined the geometrical correction factor $\mathrm{C}$ such that $\rho=\mathrm{C} \mathrm{R} t$ where $\mathrm{t}$ is the film thickness. To that aim, we have used a classical four-point probe system on a non-oriented doped P3HT film to obtain a reference value of the resistivity given by $\rho=4.53 \mathrm{Rt}$. Using this value of the resistivity we determined the geometrical correction factor for our four-line electrode geometry by measuring the sheet resistance on the same sample and obtained $C=1.81$ i.e. $\rho=1.81 \mathrm{Rt}$. The average 
conductivity value for a given doping condition and polymer was taken as the average of four devices.

Thermopower measurements were conducted on the same devices in a glove box. The thermopower was measured via the differential temperature method: a temperature gradient is established across the sample either along the rubbing direction or perpendicular to it. The measurements were performed by using a homemade setup made of one heating and one cooling Peltier cells ( $3 \mathrm{~mm}$ gap) (see reference 17 ) providing a controllable temperature difference $\Delta T$. Temperatures of the cold and warm sides were measured in a non-contact mode using two IR sensors avoiding thus thermal contact issues. The Seebeck tension was measured using a Keithley 2634B sourcemeter and a Semiprobe Lab assistant probe station in ambient conditions. The Seebeck coefficient is calculated from the slope of $V_{\text {therm }}$ versus temperature difference $\Delta T$ for $\Delta T$ varying in a range $\pm 10 \mathrm{~K}$ around $T=23 \pm 2^{\circ} \mathrm{C}$.

Calculation of doping level.

The doping level i.e. the number of $\mathrm{F}_{4} \mathrm{TCNQ}^{-}$anion per thiophene cycle was calculated at the saturation of the doping in solution from the UV-vis-NIR absorption spectra for POL $\perp$ R. To that aim, we have first determined the absorbance of the anion and used the extinction coefficient of $\mathrm{F}_{4} \mathrm{TCNQ}^{-}$reported in the literature for the $0-0$ component $\left(\varepsilon=50000 \mathrm{~L} \mathrm{~mol}^{-1}\right.$ $\mathrm{cm}^{-1}$ ) to obtain the corresponding concentration inside the thin films following the equation $\mathrm{C}_{\mathrm{F} 4 \mathrm{TCNQ}}=\mathrm{Abs}(0-0) / \varepsilon t$ where $\mathrm{t}$ is the film thickness determined from the absorbance of the undoped film. (ref) The absorbance of the 0-0 component of $\mathrm{F}_{4} \mathrm{TCNQ}^{-}$overlaps partially with the P2 polaronic band as well as the tail of the absorption of the amorphous undoped fraction of the polymer. Rather than performing an arbitrary multipeak fitting using several gaussians to account for the underlying absorbance of P2 and amorphous fraction (ref 
Salleo), we decided to use a linear baseline between $615 \mathrm{~nm}$ and $1060 \mathrm{~nm}$ (see figure SI x) to extract the absorbance of the $\mathrm{F}_{4} \mathrm{TCNQ}^{-}$anion. The volumic concentration of thiophene cycles in the films $\left(C_{\text {thiophene }}\right)$ was extracted from the volume of the unit cell of the doped phases (we assume orthorhombic unit cells with two chains per unit cell). The cell parameters of the doped phases of the PBTTTs are determined from the values of $d_{003}, d_{100}$ and $d_{020}$ of the diffraction patterns at saturation.

\section{Acknowledgments.}

Bernard Lotz is acknowledged for fruitful discussions and careful reading of the manuscript. C. Blanck and M. Schmutz are gratefully acknowledged for technical support in TEM. P. Allgayer is acknowledged for technical support with the rubbing machine and $\mathrm{N}$. Zimmermann is acknowledged for technical support in pre-patterned device preparation. Financial support from the ANR Anisotherm is gratefully acknowledged.

\section{Conflicts of interests.}

The authors declare no conflict of interest.

\section{Supporting information.}

Synthesis of polymers with different side chain lengths. Kinetics of doping followed by UVvis-NIR spectroscopy for films of PBTTTs with different side chain length and for different thicknesses. Differential Scanning Calorimetry data relative to the side chain melting/crystallization. Cyclic voltammetry data for the HOMO level determination. Correlation plots between polaron $\mathrm{P} 1$ and $\mathrm{F}_{4} \mathrm{TCNQ}^{-}$absorption bands showing integer transfer. Equatorial section profiles of electron diffraction patterns. Charge conductivity, Seebeck coefficient and power factors as a function of doping time for $\mathrm{C}_{8}$-PBTTT, $\mathrm{C}_{14}$-PBTTT 
and $\mathrm{C}_{18}$-PBTTT. Bright field TEM image of the film morphology for oriented $\mathrm{C}_{8}$-PBTTT thin films. SEM images of oriented $\mathrm{C}_{8}-\mathrm{PBTTT}$ and $\mathrm{C}_{18}$-PBTTT films.

\section{References.}

(1) Lu, G.; Blakesley, J.; Himmelberger, S.; Pingel, P.; Frisch, J.; Lieberwirth, I.; Salzmann, I.; Oehzelt, M.; Di Pietro, R.; Salleo, A.; Koch, N.; Neher, D. Moderate Doping Leads to High Performance of Semiconductor/Insulator Polymer Blend Transistors. Nat. Comm. 2013, 4, 1588-1596.

(2) Panidi, J.; Paterson, A. F.; Khim, D.; Fei, Z.; Han, Y.; Tsetseris, L.; Vourlias, G.; Patsalas, P. A.; Heeney, M.; Anthopoulos, T. D. Remarkable Enhancement of the Hole Mobility in Several Organic Small-Molecules, Polymers, and SmallMolecule:Polymer Blend Transistors by Simple Admixing of the Lewis Acid p-Dopant B(C6F5)3. Advanced Science 2017, 5 , 1700290.

(3) Slawomir, B.; R, S. W.; Mats, F. Energy-Level Alignment at Organic/Metal and Organic/Organic Interfaces. Adv. Mater. 2009, 21, 1450-1472.

(4) Bubnova, O.; Khan, Z. U.; Malti, A.; Braun, S.; Fahlman, M.; Berggren, M.; Crispin, X. Optimization of the Thermoelectric Figure of Merit in the Conducting Polymer Poly(3,4-Ethylenedioxythiophene). Nat. Mater. 2011, 10, 429.

(5) Jacobs, I. E.; Aasen, E. W.; Oliveira, J. L.; Fonseca, T. N.; Roehling, J. D.; Li, J.; Zhang, G.; Augustine, M. P.; Mascal, M.; Moule, A. J. Comparison of Solution-Mixed and Sequentially Processed P3HT: $\mathrm{F}_{4} \mathrm{TCNQ}$ Films: Effect of Doping-Induced Aggregation on Film Morphology. J. Mater. Chem. C 2016, 4, 3454-3466.

(6) Duong, D. T. ; Wang, C. ; Antono, E. ; Toney, M. F. ; Salleo, A. The Chemical and Structural Origin of Efficient P-type Doping in P3HT. Org. Elect. 2013, 14, 1330-1336.

(7) Wang, C.; Duong, D. T.; Vandewal, K.; Rivnay, J.; Salleo, A. Phys. Rev. B 2015, 91, 085205.

(8) Hynynen, J.; Kiefer, D.; Yu, L.; Kroon, R.; Munir, R.; Amassian, A.; Kemerink, M.; Müller, C. Enhanced Electrical Conductivity of Molecularly P-Doped Poly(3Hexylthiophene) through Understanding the Correlation with Solid-State Order. Macromolecules 2017, 50 (20), 8140-8148. 
(9) Scholes, D. T.; Hawks, S. A.; Yee, P. Y.; Wu, H.; Lindemuth, J. R.; Tolbert, S. H.; Schwartz, B. J. Overcoming Film Quality Issues for Conjugated Polymers Doped with F4TCNQ by Solution Sequential Processing: Hall Effect, Structural, and Optical Measurements. J. Phys. Chem. Lett. 2015, 6, 4786-4793.

(10)

Scholes D. Tyler; Yee Patrick Y.; Lindemuth Jeffrey R.; Kang Hyeyeon; Onorato Jonathan; Ghosh Raja; Luscombe Christine K.; Spano Frank C.; Tolbert Sarah H.; Schwartz Benjamin J. The Effects of Crystallinity on Charge Transport and the Structure of Sequentially Processed F4TCNQ-Doped Conjugated Polymer Films. Adv. Funct. Mater.2017, 27, 1702654.

Méndez, H.; Heimel, G.; Winkler, S.; Frisch, J.; Opitz, A.; Sauer, K.; Wegner, B.; Oehzelt, M.; Röthel, C.; Duhm, S.; Többens, D.; Koch, N.; Salzmann, I. Charge-Transfer Crystallite as Molecular Electrical Dopants. Nature Communications 2015, 6, 8560. Pingel, P.; Neher, D. Comprehensive Picture of p-Type Doping of P3HT with the Molecular Acceptor $\mathrm{F}_{4}$ TCNQ. Phys. Rev. B 2013, 87, 115209. Hynynen, J.; Kiefer, D.; Muller, C. Influence of Crystallinity on the Thermoelectric Power Factor of P3HT Vapour-Doped with $\mathrm{F}_{4}$ TCNQ. RSC Adv. 2018, 8, 1593-1599.

Patel, S. N.; Glaudell, A. M.; Peterson, K. A.; Thomas, E. M.; O’Hara, K. A.; Lim, E.; Chabinyc, M. L. Morphology Controls the Thermoelectric Power Factor of a Doped Semiconducting Polymer. Science Advances 2017, 3, e1700434.

Hartmann, L.; Tremel, K.; Uttiya, S.; Crossland, E.; Ludwigs, S.; Kayunkid, N.; Vergnat, C.; Brinkmann, M. 2D Versus 3D Crystalline Order in Thin Films of Regioregular Poly(3-Hexylthiophene) Oriented by Mechanical Rubbing and Epitaxy. Adv. Funct. Mater. 2011, 21, 4047-4057. Hamidi-Sakr, A.; Biniek, L.; Fall, S.; Brinkmann, M. Precise Control of Lamellar Thickness in Highly Oriented Regioregular Poly(3-Hexylthiophene) Thin Films Prepared by High-Temperature Rubbing: Correlations with Optical Properties and Charge Transport. Adv. Funct. Mater. 2016, 26, 408-420. Hamidi-Sakr, A.; Biniek, L.; Bantignies, J.-L.; Maurin, D.; Herrmann, L.; Leclerc, N.; Leveque, P.; Vijayakumar, V.; Zimmermann, N.; Brinkmann, M. A Versatile Method to Fabricate Highly In-Plane Aligned Conducting Polymer Films with 
Anisotropic Charge Transport and Thermoelectric Properties: The Key Role of Alkyl Side Chain Layers on the Doping Mechanism. Adv. Funct. Mater. 2017, 27 , 1700173.

McCulloch, I.; Heeney, M.; Bailey, C.; Genevicius, K.; MacDonald, I.; Shkunov, M.; Sparrowe, D.; Tierney, S.; Wagner, R.; Zhang, W.; Chabinyc, M. L.; Kline, R. J.; McGehee, M. D.; Toney, M. F. Liquid-Crystalline Semiconducting Polymers with High Charge-Carrier Mobility. Nat. Mater. 2006, 5, 328-333.

(19) Cho, E. ; Risko, C. ; Kim, D. ; Gysel, R. ; Miller, N. C. ; Breiby, D. W. ; McGehee, M. D. ; Toney, M. F.; Kline, R. J. and Brédas, J.-L. Three-Dimensional Packing Structure and Electronic Properties of Biaxially Oriented Poly(2,5-bis(3alkylthiophene-2-yl)thieno[3,2-b]thiophene) Films. J. Am. Chem. Soc. 2012, 134, 6177-6190.

(20) DeLongchamp, D. M.; Kline, R. J.; Jung, Y.; Germack, D. S.; Lin, E. K.; Moad, A. J.; Richter, L. J.; Toney, M. F.; Heeney, M.; McCulloch, I. Controlling the Orientation of Terraced Nanoscale "Ribbons" of a Poly(Thiophene) Semiconductor. ACS Nano 2009, 3, 780-787.

(21) Biniek, L.; Leclerc, N.; Heiser, T.; Bechara, R.; Brinkmann, M. Large Scale Alignment and Charge Transport Anisotropy of PBTTT Films Oriented by High Temperature Rubbing. Macromolecules 2013, 46, 4014-4023.

(22) Biniek, L.; Pouget, S.; Djurado, D.; Gonthier, E.; Tremel, K.; Kayunkid, N.; Zaborova, E.; Crespo-Monteiro, N.; Boyron, O.; Leclerc, N.; Ludwigs, S. and Brinkmann, M. High-Temperature Rubbing: A Versatile Method to Align $\pi$-Conjugated Polymers without Alignment Substrate. Macromolecules 2014, 47, 3871-3879.

Brinkmann, M.; Hartmann, L.; Biniek, L.; Tremel, K.; Kayunkid, N. Orienting Semi-Conducting Pi-Conjugated Polymers. Macromolecular Rapid Communications 2014, 35, 9-26.

Ghosh, R.; Pochas, C. M.; Spano, F. C. Polaron Delocalization in Conjugated Polymer Films. J. Phys. Chem. C 2016, 120, 11394-11406.

Ghosh, R.; Chew, A. R.; Onorato, J.; Pakhnyuk, V.; Luscombe, C. K.; Salleo, A.; Spano, F. C. Spectral Signatures and Spatial Coherence of Bound and Unbound Polarons in P3HT Films: Theory Versus Experiment. J. Phys. Chem. C 2018, 122, 18048-18060. 

films, the reader is invited to consider reference 17 showing that it is a characteristic feature of the anion $\mathrm{F}_{4} \mathrm{TCNQ}^{-}$and not of neutral $\mathrm{F}_{4} \mathrm{TCNQ}$

H. Mehrer in Diffusion in Solids. Fundamentals, Methods, Materials, Diffusionlimited Processes, Springer Series in Solid-State Sciences, Springer Verlag, 2007, 4145.

Maliakal, A. J. Characterization of Dopant Diffusion within Semiconducting Polymer and Small-Molecule Films Using Infrared-Active Vibrational Modes and Attenuated Total Reflectance Infrared Spectroscopy. ACS Appl. Mater. Interfaces 2013, 5 (17), 8300-8307.

D. M. DeLongchamp, R. J. Kline, Y. Jung, E.K. Lin, D. A. Fischer, D. J. Gundlach, S. K. Cotts, A. J. Moad, L. J. Richter, M. F. Toney, M. Heeney, and I. McCulloch Macromolecules 2008, 41, 5709-5715

(30) Kayunkid, N.; Uttiya, S.; Brinkmann, M. Structural Model of Regioregular Poly(3-Hexylthiophene) Obtained by Electron Diffraction Analysis. Macromolecules 2010, 43, 4961-4967.

Dorset, L. D. in Crystallography of the polymethylene chain : an inquiry into the structure of waxes, IUCr Monographs on crystallography $n^{\circ} 17$, Oxford University Press, New York, 2005, pp. 19-28. Miller, N. C.; Cho, E.; Junk, M. J. N.; Gysel, R.; Risko, C.; Kim, D.; Sweetnam, S.; Miller, C. E.; Richter, L. J.; Kline, R. J.; Heeney, M.; McCulloch, I.; Amassian, A.; Acevedo-Feliz, D.; Knox, C.; Hansen, M. R.; Dudenko, D.; Chmelka, B. F.; Toney, M. F.; Brédas, J.-L.; McGehee M. D. Use of X-Ray Diffraction, Molecular Simulations, and Spectroscopy to Determine the Molecular Packing in a Polymer-Fullerene Bimolecular Crystal. Adv. Mater. 2012, 24, 6071-6079.

Wang, C.; Duong, D. T.; Vandewal, K.; Rivnay, J.; Salleo, A. Optical Measurement of Doping Efficiency in Poly(3-Hexylthiophene) Solutions and Thin Films. Phys. Rev. B 2015, 91 (8), 085205. Dixon, D. A.; Calabrese, J. C.; Miller, J. S. Crystal and Molecular Structure of the 2:1 Charge-Transfer Salt of Decamethylferrocene and Perfluoro-7,7,8,8- 
Tetracyano-p-Quinodimethane: [[Fe(C5Me5)2]+.Cntdot.]2[TCNQF4]2-. The Electronic Structure of [TCNQF4]n ( $\mathrm{n}=0$, 1-, 2-). J. Phys. Chem. 1989, 93 (6), 2284-2291. Fujimoto, R.; Yamashita, Y.; Kumagai, S.; Tsurumi, J.; Hinderhofer, A.; Broch, K.; Schreiber, F.; Watanabe, S.; Takeya, J. Molecular Doping in Organic Semiconductors: Fully Solution-Processed, Vacuum-Free Doping with Metal-Organic Complexes in an Orthogonal Solvent. J. Mater. Chem. C 2017, 5 (46), 12023-12030. Patel, S. N.; Glaudell, A. M.; Kiefer, D.; Chabinyc, M. L. Increasing the Thermoelectric Power Factor of a Semiconducting Polymer by Doping from the Vapor Phase. ACS Macro Lett. 2016, 5, 268-272.

Kang, K.; Watanabe, S.; Broch, K.; Sepe, A.; Brown, A.; Nasrallah, I.; Nikolka, M.; Fei, Z.; Heeney, M.; Matsumoto, D.; Marumoto, K.; Tanaka, H.; Kuroda, S.; Sirringhaus, H. 2D coherent charge transport in highly ordered conducting polymers doped by solid state diffusion. Nat. Mater. 2016, 15, 896-902.

Kline, R. J.; McGehee, M. D.; Kadnikova, E. N.; Liu, J.; Fréchet, J. M. J.; Toney, M. F. Dependence of Regioregular Poly(3-Hexylthiophene) Film Morphology and Field-Effect Mobility on Molecular Weight. Macromolecules 2005, 38, 3312-3319. Pukacki, W.; Płocharski, J.; Roth, S. Anisotropy of Thermoelectric Power of Stretch-Oriented New Polyacetylene. Synthetic Metals 1994, 62 (3), 253-256. Kaiser, A. B. Thermoelectric Power and Conductivity of Heterogeneous Conducting Polymers. Phys. Rev. B 1989, 40 (5), 2806-2813. Wei, Q.; Mukaida, M.; Kirihara, K. and Ishida, T. Experimental Studies on the Anisotropic Thermoelectric Properties of Conducting Polymer Films. Macro Lett. 2014, 3. 948.

(42) Kulkarni, A. P.; Tonzola, C. J.; Babel, A.; Jenekhe, S. A., Electron Transport Materials for Organic Light-Emitting Diodes. Chemistry of Materials 2004, 16 (23), 4556-4573. Glaudell, A. M.; Cochran, J. E.; Patel, S. N.; Chabinyc, M. L. Impact of the Doping Method on Conductivity and Thermopower in Semiconducting Polythiophenes. Adv. Energy Mater. 2015, 5, 1401072. 
(44) Kang, S. D.; Snyder, G. J. Charge-Transport Model for Conducting Polymers. Nat. Mater. 2016, 16, 252-257. 